Ministerstwo Nauki

i Szkolnictwa Wyższego

Digitalizacja archiwalnych numerów czasopisma naukowego Analecta Cracoviensia 1-24 (1969-1992)

i ich publikacja w otwartym dostępie - zadanie finansowane w ramach umowy 672/P-DUN/2017 ze środków

Ministra Nauki i Szkolnictwa Wyższego przeznaczonych na działalność upowszechniającą naukę

\title{
WYPISY DO BIOGRAFII JANA DEUGOSZA Z KSIĄG SĄDOWYCH KURII METROPOLITALNEJ W KRAKOWIE
}

\author{
W s tęp
}

Michał Bobrzyński i Stanisław Smolka dołączyli do swojego dzieła - Janie Długoszu regesty, które stanowią repertorium źródeł do jego biografii ${ }^{1}$. Wśród nich znalazły się także zapiski z ksiąg konsystorza krakowskiego. Robiąc kwerendę do historii Uniwersytetu Krakowskiego wypisałam z nich jeszcze około 70 nieznanych dotąd zapisek, nie licząc tych, w których Długosz występuje tylko w formule świadków. Kwerenda ta, być może nie wyczerpuje jeszcze wszystkiego, co do biografii Długosza zawierają Acta officialia i Acta episcopalia ${ }^{2}$. Mimo to zdecydowałam się na wydanie tego jakby uzupełnienia regestów Bobrzyńskiego i Smolki. Niektórzy historycy są przeciwni publikowaniu w wyborze materiału źródłowego z ksiąg sądowych, ale przecież nie zanosi się na wydanie całych ksiąg, wypisy zaś - przykładem te do dziejów Wawelu zrobione przez ks. Bolesława Przybyszewskiego ${ }^{3}$ - są bardzo użyteczne w badaniach historycznych.

$\mathrm{Na}$ łamach ksiąg sądowych konsystorza krakowskiego Długosz pojawił się w związku z funkcjami pełnionymi przy boku Zbigniewa Oleśnickiego, zostając w r. 1431 notariuszem, czyli po prostu pisarzem w jego kancelarii. Następnie był kolejno sekretarzem i kanclerzem biskupa krakowskiego. Pracując i przebywając stale w konsystorzu bywał, podobnie jak inni notariusze i zatrudnieni w nim pracownicy, powoływany na świadka $\mathrm{w}$ toczących się tam sprawach, wpisywanych do ksiąg. W czasie np. od

1 M. Bobrzyński, S. Smolka, Jan Dlugosz. Jego życie i stanowisko w piśmiennictwie, Kraków 1893, s. 215-312. Zob. też A. Perzanowska, Wiadomości źródtowe o życiu i działalności Jana Dlugosza w: Dlugossiana Kraków 1980, s. 293-365.

2 Zob. B. Przybyszewski, Wypisy źródłowe do dziejów Wawelu z archiwaliów kapitulnych i kurialnych krakowskich. Z. 1: 1440-1500, Kraków 1960, s. VI--VII; J. Kracik, Zasoby Archiwum Kurii Metropolitalnej w Krakowie. ,Analecta Cracoviensia " 9 (1977), s. $473 \mathrm{nn} ., 481 \mathrm{nn}$.

3 Zob. przypis 2. 
18 XI 1450 - 18 VI 1451 w formułach świadków Długosz występuje ok. 50 razy ${ }^{4}$.

Wydane poniżej zapiski są różnej wartości źródłowej, podobnie zresztą jak te wydane uprzednio przez Bobrzyńskiego i Smolkę. Niektóre dotyczą spraw znanych już z regestów lub z innych źródeł. Są i takie, które odnoszą się- wyłącznie do procedury sądowej ${ }^{5}$ i wymieniają zaledwie osoby występujące $\mathrm{w}$ danej sprawie. Niemniej wszystkie stanowią przyczynki do biografii Jana Długosza, którego 500-letnią rocznicę śmierci właśnie święcimy.

Przy boku Jana seniora występuje często jego młodszy brat, również Jan, kanonik krakowski, zmarły w r. 1471. W sprawach prowadzonych przez brata-historyka bywał jego zastępcą prawnym i świadkiem. Nie wydajemy natomiast tych zapisek, które są śladem jego osobistej działalności. Z ksiąg sądowych poznajemy także domowników Jana Długosza seniora, jego notariuszy i wikariuszy. Z grona tych ostatnich rekrutowali się kopiści jego dzieł. Jednym z nich był Krzysztof z Dębowca. Długosz posıwał go $\mathrm{w}$ godnościach, a na koniec zrobił jednym $\mathrm{z}$ wykonawców swojej ostatniej woli. Występuje też Piotr z Kęt, zwany Pietrzyk, i kilku innych. Z zapisek tych wyłania się również grono osób, z którymi Długosz był w bliższych kontaktach. Są to późniejsi biskupi (Jakub z Sienna. Jan Gruszczyński, Jan Gosławski), profesorowie (Jakub z Szadka, Maciej z Sąspowa, Mikołaj syn Spicymira z Krakowa), kanonicy (Stanisław Swiradzki, Jan Wojszyk, Jan Kazimierskí).

Najwięcej wydanych zapisek dotyczy transakcji gospodarczych i finansowych. W r. 1458 bracia Długoszowie sprzedali swoje działy we wsiach Popów i Rembielice (koło Kłobucka) Hinczy z Rogowa. Ten zaś oddał dochody z nich kościołowi w Krzepicach, zamieniając go z parafialnego na klasztorny. Mieszczanie sławkowscy w r. 1455 zakupili na kredyt u Długosza 17 bałwanów soli, pochodzących może z zastawu. Dużo zachodu poświęcał Długosz spieniężaniu dziesięcin, z których korzystał $\mathrm{z}$ racji posiadanych przez siebie prebend $\mathrm{w}$ katedrze krakowskiej oraz w kolegiacie sandomierskiej i wiślickiej. Dziesięciny te skupywała szlachta, sołtysi, a także chłopi, zobowiązując się zapłacić należność w wyznaczonym terminie. Długosz sam nie zaciągał pożyczek. Natomiast w Acta officialia występuje wiele razy (nieraz ze swoim bratem) jako wierzyciel, pożyczający duże sumy pieniężne za poręczeniami i pod zastaw. Dłużnikami jego byli duchowni, szlachata, mieszczanie krakowscy i chłopi. Często występował też jako poręczyciel.

Zapiski przynoszą wiele szczegółów do powiązań z bratankiem Oleśnickiego Jakubem z Sienna. Długosz darzył go specjalną sympatią, prowadził jego sprawy, pożyczał mu duże sumy pieniężne (nawet do 1000 florenów), popierał w zabiegach i walce o biskupstwo krakowskie, czym zraził

\footnotetext{
4 Acta officialia 9, s. 45-132.

5 Terminologię sądową, utrudniającą często zrozumienie sensu zapisek, dokładnie omówił B. Przybyszewski (jw., t. 2, s. XXVIII-XXXVII).
} 
do siebie króla i wraz z Jakubem popadł w niełaskę królewską. Długosz, jako jeden $\mathrm{z}$ egzekutorów testamentu Zbigniewa Oleśnickiego, bardzo dużo wysiłku musiał włożyć w egzekwowanie należności od dłużników kardynała, aby pieniądze mogły być użyte zgodnie $z$ wolą zmarłego. Był też wykonawcą testamentów kanonika Mikołaja Zapolickiego, proboszcza proszowickiego, i Katarzyny Stymbarskiej.

Długosz bywał powoływany do załatwiania różnych spraw. W r. 1467 razem z Mikołajem, synem Spicymira, przeprowadził transakcję zakupu dla biskupa krakowskiego Żabiego Młyna na Prądniku Czerwonym. Razem z przedstawicielami kapituły krakowskiej występował w sprawie kleryka Mojżesza, ujętego za ekscesy przez służbę Jakuba z Dębna, kaszte-lana i starosty krakowskiego, i oddanego v ręce rajców krakowskich. Za Mojżesza ręczył stryj Florian, pieban u Św. Szczepana w Krakowie. W starszym wieku Dlugosz rozstrzygał różne spory. Był jednym z arbitrów w sporzz biskupa krakowskiego z plebanem w Czemiernikach pod Lublinem o dziesięciny. Występował też w sporze o prawo prezenty na prebendę Św. Filipa i Jakuba na. Klepárzu. W związku z testamentem magistra Jana Progera, proboszcza u Św. Anny w Krakowie, i jego fundacjami, przeprowadził ugodę z krewnymi, roszczącymi sobie pretensje do spadku po zmarłym. Godził tez mieszczan krakowskich Macieja Bassaka z Janem Białym i jego żoną.

Przytoczony w całości w aktach list Jana Długosza, już elekta lwowskiego z 15 XII 1479, do biskupa krakowskiego Jana Rzeszowskiego dotyczy fundacji mansjonarzy sandomierskich. Pełen żalu i goryczy odpowiada w nim Długosz na zarzuty kapituły krakowskiej, stawiane mu w związku z użyciem 1500 florenów z legatu Tomasza Strzempińskiego na zakup dziesięcin należących do uposażenia arcybiskupa gnieźnieńskiego z dziesięciu wsi (Potworów, Wola Potworowska, Długie, Dłuska Wola, Kaszów, Kaszowska Wola, Gutów, Gutowska Wola i Czarnocin). Po śmierci Gruszczyńskiego dziesięciny te zostały zatrzymane i po czterech latach odzyskane przez Długosza. Przy tej okazji Długosz przypomniał swoje zasługi dla mansjonarzy sandomierskich: zakupienie wsi Okalin i Gojców, wymurowanie jednego domu oraz zakupienie drugiego razem $\mathrm{z}$ ogrodem.

Ostatnie zapiski z lat 1488-1497 odnoszą się już do spraw związanych z wykonaniem testamentu Dlugosza. Egzekutorami jego ostatniej woli był wikariusz generalny i oficjał krakowski Stanisław Swiradzki, kanonik krakowski, późniejszy biskup, Jan Gosławski herbu Wieniawa, prawdopodobnie krewniak Długosza, oraz wspomniany już Krzysztof z Dębowca. Sprawy spadkowe ciągnęły się jeszcze w r. 1505.

Wydane poniżej zapiski, przynosząc nowe szczegóły do biografii Jana Długosza, potwierdzają jego ruchliwość i specjalne zamiłowania gospodarcze. Był gorliwym włodarzem, umiał zdobywać i gromadzić pieniądze, które potem mógł przeznaczyć na pobożne cele, a także na uniwersyteckie fundacje.

Na koniec dziękuję serdecznie Archiwum Kurii Metropolitalnej w Krakowie za udostępnienie mi potrzebnych ksiąg, natomiast Pani doc. dr $\mathrm{Da}$ - 
nucie Turkowskiej za koleżeńską pomoc przy ustalaniu tekstu zapisek, a Pracowni Słownika Historyczno-Geograficznego PAN za pomoc przy identyfikacji osób.

* * * *

W przypisach zastosowano następujące skróty wydawnictw źródłowych i zbiorów archiwalnych:

Acta rectoralia - Acta rectoralia almae Universitatis studii Cracoviensis inde ab anno 1469. Ed. W. Wisłocki. T. 1, Kraków 1893.

AGZ - Akta grodzkie i ziemskie z czasów Rzeczypospolitej Polskiej z Archiwum tak zwanego Bernardyńskiego we Lwowie. T. 1-25, Lwów 1868--1935 .

AS - Album Studiosorum Universitatis Cracoviensis. T. 1: 1400-1489, Cracoviae 1887.

Cod. Ep. - Codex epistolaris saeculi decimi quinti. Ed. A. Sokolowski, J. Szujski, A. Lewicki. T. 1-3, Kraków 1876-1894.

Cracovia artificum - Cracovia artificum 1300-1500. Wyd. J. Ptaśnik, Kraków 1917.

DokKKr - Zbiór dokumentów katedry i diecezji krakowskiej. Wyd. S. Kuraś. Cz. 2: 14161450, Lublin 1973.

Episcop. Crac. - Acta episcopalia Curiae Metropolitanae Cracoviensis.

Fedorowicz - K. Fedorowicz, Dostojnicy i urzęanicy województwa krakowskiego w latach 1374-1506, [w:] Archiwum Komisji Historycznej AU. T. 8, Kraków 1898.

Kod. UJ - Codex diplomaticus Universitatis studii generalis Cracoviensis. Pars I-V, Kraków 1870-1900.

Kod. wiel. - Kodeks dyplomatyczny wielicki. Wyd. A. Rudyński, Lwów 1872.

Kory九kowski - J. Korytkowski, Prałaci i kanonicy katedry metropolitalnej gnieźnieńskiej od r. 1000. T. 1-4, Gniezno 1883.

Lib. Ben. - Ioannis Dlugosz senioris canonici Cracoviensis liber beneficiorum dioecesis Cracoviensis. T. 1-3, Kraków 1863-1864.

LP - Statuta nec non Liber promotionum philosophorum ordinis in Universitate studiorum Jagellonica ab anno 1402 ad annum 1849: Ed. J. Muczkowski, Kraków 1849.

Mat. PSH-G PAN - Materiały Pracowni Słownika Historyczno-Geograficznego Polskiej Akademii Nauk, Oddział w Krakowie.

Offic. Crac. - Acta officialia Curiae metropolitanae Cracoviensis.

Przybyszewski, Wypisy - B. Przybyszewski, Wypisy źródłowe do dziejów Wawelu, t. 1-2, Kraków 1960-1965.

Przybyszewski, Złoty dom - B. Przybyszewski, Złoty dom królestwa, Warszawa 1968.

PSB - Polski Słownik Biograficzny.

Regesta (BS) - M. Bobrzyński, S. Smolka, Jan Długosz. Jego życie i stanowisko w piśmiennictwie, Kraków 1893, s. 215-312.

StPPP - Starodawne Prawa Polskiego Pomniki. Wyd. A. Z. Helcel i in., t. 1-13, Warszawa 1856-1921. 


\section{TEXT US}

Joannis Dlugosch canonici Cracoviensis ad instanciam Johannes [de] Prosch[owicze] retulit se citasse de mandato domini Albertum Pyka ${ }^{1}$ procuratorem Nikel de Veliczka ${ }^{2}$ ad respondendum libello, cui terminum ad horam presentis diei assignavit. Qui peremptorie respondebit I die iuris. Presentibus supra.

Offic. Crac. 5 k. $266 r$.

2

26 V 1438

Johannis Dlugossii canonici Cracoviensis et Nicolai carnificis de Veliczka magister Petrus ${ }^{1}$ nomine dicti Johannis libellum statim repeciit, loco articulorum petens admitti. Et dominus admisit terminumque proxima dilacione ad XV diem statuit et prefixit. Presentibus supra.

Offic. Crac. 5.k. $267 v$.

3

$3 \times 1444$

Jacobus Woyniczsky ${ }^{1}$ principalis debitor prepositus Cracoviensis et $\mathrm{Ni}$ colaus Spiczmeri ${ }^{2}$ cantor ac Johannes Dlugossii canonicus Cracoviensis, ipsius fideiussores, omnes in solidum et manu coniuncta obligarunt se venerabili domino Andree Miska ${ }^{3}$ scolastico Gneznensis et canonico Cracoviensis ecclesiarum centum florenos in auro certi mutui, ad Purificacionis proxime venturum, Hungaricales iusti ponderis, sub pena excommunicacionis soluturos. Presente domino Mathia ${ }^{4}$ prothonotario et vicario.

Offic. Crac. 8 s. $654-655$.

Iohannem Galka de Mydzwiecz ${ }^{1}$ Stanislaus de Opol 2 procurator nomine procuratorie eiusdem obligavit octo marcas peccunie racione caucionis fi-

11 Albertus Pyka ze Skalbmierza (1437-1438): Regesta (BS) nr 15; Przybyszewski, Ztoty dom, s. 93.

2 Mikołaj Nikiel, rzeźnik, mieszczanin wielicki (1438): Regesta (BS) nr 15, 17, 18. 21 Piotr z Proszowic, notariusz publiczny, magister artium Uniwersytetu Krakowskiego (1420), prokurator konsystorza krakowskiego (1424). W aktach występuje do r. 1449: Regesta (BS) nr 17; DokKKr II, s. 36.

31 Jakkub z Sienna (Sieneński), prepozyt gnieźnieński i krakowski (1444), biskup krakowski (1461-1463), biskup wrocławski (1464), arcybiskup gnieźnieński (1473-1480): Przybyszewski, Wypisy I, s. 16.

2 Mikołaj, syn Spicymira z Krakowa, doktór dekretów, kantor krakowski, dziekan poznański, pleban parafii Wszystkich Swiętych w Krakowie, kolektor denara św. Piotra. W aktach kapitulnych krakowskich występuje do r. 1469: Przybyszewski, Wypisy I, s. 2.

3 Andrzej Myszka z Nieprześnej, archidiakon (1413) i oficiał krakowski (1415), kowski (1444), biskup kujawski (1450) i krakowski (1463), arcybiskup gnieźnieṅski scholastyk gnieźnieński (1427), zm. w r. 1446: Korytkowski III, s. 61-65,

4 Maciej, syn Mikołaja z Grodźca, notariusz publiczny (1439), wikariusz katedralny kraḱkowski (1448), altarysta św. Katarzyny w kościele NMP w Krakowie, kanonik kolegiaty sądeckiej (1461) i sandomierskiej (1466), w r. 1477 wspomniany jako zmarły: DokKKr II, s. 308.

4 ' 1 Jan Gałka z Niedźwiedzia h. Ođrowąż, wielkorządca krakowski (1442-1444): Fedorowicz, s. 149.

2 Stanisław z Opola, prokurator konsystorza krakowskiego $(1440-1465)$ : Przybyszewski, Złoty dom, s. 158; Kod. UJ II, s. 47, 240. 
deiussorie pro domino Iohanne Gruschczinsky ${ }^{3}$ per ipsum facte venerabili domino Iohanni Dlugossi canonico Cracoviensi et cancellario domini episcopi Cracoviensis sub pena excommunicacionis ad festum Nativitatis Christi proximum soluturum. Presentibus in actis.

Offic. Crac. 8 s. 666.

Nicolaus Spiczmyr de Cracovia cantor et Iohannes Dlugosch canonicus Cracovienses etc. manu coniuncta pro domino Iacobo de Schenno preposito Cracoviensi fideiubendo obligarunt se sponte venerabili domino Andree Miska scolastico Gneznensis et canonico Cracoviensis etc. ecclesiarum ex causa veri et certi mutui centum florenos cum quatuor necnon sexaginta marcas mediantum vel alias harum valorem verum ad quindenam post festum s. Martini proxime venturum sub pena excomunicacionis soluturos et daturos. Quos quidem centum florenos cum quatuor et sexaginta marcas alias eorum valorem, scilicet ducentos florenos, venerabilis dominus Iohannes de Elgoth ${ }^{1}$, decretorum doctor, scolasticus Cracoviensis a dicto domino Andrea nomine dictorum dominorum Nicolai et Iohannis recognovit se recepisse cum effectu, prout est ad id sibi coram me notario data sibi potestas per eosdem, scilicet ad recipiendum. Presentibus dominis Nicolao Woyniczski 2 canonico Cracoviensi, Nicolao Leymertum ${ }^{3}$ magistro arcium, Clemente et Paulo notariis de Omnibus Sanctis, Georgio de Michnowicze et Paulo de Jeschow ${ }^{4}$ et Mathia protonotario publico et aliis pluribus circa hoc.

Offic. Crac. 8 s. $786-787$.

6

8 VIII 1446

Iohannes nobilis Lubyerthowski ${ }^{1}$ obligavit soluturum domino Dlugossio canonico Cracoviensi quindecim marcas occasione decimarum in villis Swola, Thomaskowicze, Grayów, Racziborsko ${ }^{2}$ ad festum s. Stanislai in Maio proximum sub penis excommunicacionis. Presentibus domino doctore Oskowsky $^{3}$, Stanislao vicario de Castro.

Offic. Crac. 8 s. 869.

3 Jan Gruszczyński z Gruszczyc h. Poraj, kanonik gnieźnieński, kustosz krakowski (1444), biskup kujawski (1450) i krakowski (1463), arcybiskup gnieźnieński (1464), zm. w r. 1473: PSB IX, s. 55-57.

$5 \quad 1$ Jan Elgot, syn Dobka ze Lgoty h. Wieniawa, doctor dekretów Uniwersytetu Krakowskiego (1424), kanonik (1430), oficjał (1433), wikariusz generainy i scholastyk krakowski (1438), zm. w r. 1452: PSB VI, s. 227.

2 Mikołaj Wojnicki (z Wojnicza), kanonik krakowski (1443), scholastyk wiślicki. W aktach kapituły krakowskiej występuje do r. 1459: Przybyszewski, Wypisy I, s. 4.

3 Mikołaj Leymeter z Krakowa, bakałarz artium Uniwersytetu Krakowskiego (1444-1455): LP 30, 35; B. Chmielowska, Z. Włodek, Maciej z Łabiszyna [w:] Materiały do Historii Filozofii Średniowiecznej w Polsce, t. 4, Wrocław 1971, s. 46; Cracovia artificum nr 429, 485.

4 Pawel, syn Jana z Jeżowa, notariusz publiczny i kapituly krakowskiej, wikariusz katedralny krakowski, występuje w 1. 1447-1460: DokKKr II, s. 520.

61 Jan Lubertowski (Lubiertowski) szlachcic (1439-1442): StPPP II nr 2828, 3070; Cod. Ep. II, s. 889.

2 Wolica (Swola), Tomaszkowice, Grajów i Raciborsko - wsie koło Wieliczki, pow. szczyrzycki, z których dziesięciny należały do kanonii i prebendy gonowskiej: Lib. Ben. I, S. $142-143$.

3 Jan Oszkowski z Dobrej, profesor medycyny Uniwersytetu Krakowskiego, zm. w r. 1447: PSB X, s. 449-450. 
Myrek de Raczyborsko cmetho obligavit se soluturum tres cum media marcas communis pecunie infra hinc ad festum s. Stanislai in Maio honorabili domino Dlugossyo canonico Cracoviensi sub pena excommunicacionis. Presentibus Iohanne Craszka, Iohanne Sartore, Iohanne de Syrnyczky.

Offic. Crac. 8 s. 924.

8

15 XII 1446

Swanch de Swolya obligavit se soluturum septem fertones communis peccunie venerabili domino Iohanni Dlugosch canonico Cracoviensi pro decima in ibidem ad festum s. Stanislai in Mayo proxime affuturum sub pena excommunicacionis. Presentibus Paulo notario et Mathia protonotario.

Offic. Crac. 8 s. $924-925$.

Bartek de Grayewo obligavit se soluturum tres cum media marcas communis pecunie venerabili viro Iohanni Dlugosch canonico Cracoviensi pro decima ibidem infra hinc ad festum s. Stanislai in Maio proxime venturum sub pena excommunicacionis. Presentibus Paulo notario et Mathia protonotario et Iohanne plebano in Crobya.

Offic. Crac. 8 s. 925 .

Nicolaus ${ }^{1}$ advocatus in Cleparz obligavit se soluturum sedecem marcas communis peccunie venerabili viro domino Iohanni Dlugosch canonico Cracoviensi pro decima apud ipsum empta in villa dicta Radzycze ${ }^{2}$ (!) ad prefatum ipsius canonicatum spectantem et pertinentem sub pena excommunicacionis. Presentibus supra.

Offic. Crac. 8 s. 934 .

11

7 IV 1451

Barthek kmetho de Grayow pro decima in ibidem empta apud dominum Swantoslaum prebendarium de Proschowicze ad dominum Iohannem Dlugosch et suam prebendam Cracoviensem pertinente duas sexagenas peccuniarum ad festum Ascensionis Domini proximum eidem domino Swantoslao aut domino Iohanni Dlugosch prefato solvere obligavit sub pena excommunicacionis. Presentibus quibus supra. 2:

Offic. Crac. 9 s. 107.

Thomas diaconus arcium baccalarius de Bochnya ${ }^{1}$ obligavit se solvere decem et septem grossos communis pecunie occasione mitre nigri coloris empte honorabili Iohanni Dlugosch plebano de Clobuczsko octava die post

101 Mikołaj z Zaszczytowa, wójt kleparski (1442-1449): Kod. UJ II, S. $15,120$.

2 Radziemice w pow. proszowickim. Dziesięcina z nich należała do kanonii i prebendy więcławskiej: Lib. Ben. I, s. 98.

121 Tomasz z Bochni, bakałarz atrium Uniwersytetu Krakowskiego (1438), notariusz (1440): LP, s. 31; Cracovia artificum, nr 362. 
festum s. Stanislai in Mayo proximum sub pena excommunicacionis soluturum. Presentibus quibus supra.

Offic. Crac. 9 s. 110.

13

1 IV 1452

Niccolaum Szysszno, Iohannem Osszeczsky de Cracovia, Falibogium et Iohannem Bankyel ${ }^{1}$ de Wyelyczca dominus Iohannes Dlugosch plebanus de Clobuczsko nomine reverendi patris domini Iacobi de Senno etc. prepositi Cracoviensis de viginti marcis pecunie communis, quas ab eis confessus est cum effectu recepisse, quittavit et absolvit ac ob spem solucionis residui, puta triginta et sex marcarum, ad festum Penthecostes proximum fiende sub reduccione pristinarum excommunicacionis, aggravacionis etc. contra participando in absolucionem consensit. Presentibus Paulo Gezewo, Jacobo Strzeszich, Iohanne Pyekarsky 2 .

Offic. Crac. 9 s. 277.

Jacobus de Senno prepositus Cracoviensis et Scarbimiriensis debitor principalis ac Johannes Dlugosch custos Wisliciensis et canonicus Cracoviensis pro eo fideiussor septuaginta marcas peccuniarium residuas monete minute alias olim nobili Helwigo de Besdzedza ${ }^{1}$ debitas et obligatas nobilibus Laczlao de Jodlownik ${ }^{2}$, Petro Rozembarsky ${ }^{3}$ et Nicolao Rokosch de Cosczicze ${ }^{4}$ tamquam successoribus dicti Helwigi et generis ad nunc venturum sancti Stanislai in Mayo festum sub excommunicacionum penis solvere obligarun $\hat{\imath}$, omnibus dilacionibus, allegacionibus, excepcionibus, appellacionibus, viis, modis et coloribus dilacionem importantibus renunciando. Quiquidem nobiles Laczslaus Veronice, Petrus Rozembarsky Elizabeth uxorum suarum ac Nicolaus Rokosch Regnoche sue genitricis nominibus filiarum dicti Hedwigi (!) omnes obligaciones et inscripciones predicto Heluigo, dum agebat in humani, factas per ipsos dominos Jacobum de Senno et Johannem Dlugosch anullando, extinguendo et mortificando ac eosdem dominos debitores ac ab ipsis eorum uxoribus ipsarumque aliis sororibus et aliis quibuscumque extraneis et propinquis personis ad pecunias huiusmodi propinquitatem habentibus seu habere pretendentibus evincere ac ab impedimentis et dampnis liberare expedire et indempnes reddere ex nunc sub excommunicacionis penis se obligarunt. Presentibus dominis Petro Czesla ${ }^{5}$ canonico Cracoviensi, Johanne Sbigneowsky plebano in Baranow et Paulo Czanstkowsky ${ }^{6}$ notario publico.

Offic. Crac. 9 s. 369.

131 Jan Bankiel, mieszczanin wielicki (1443): Kod. Wiel., s. 26.

2 Jan Piekarski, pleban w Pleszowie (1467): Cod. Ep. III, s. 108.

141 Helwig z Bezdziedzy (pow. pilzneński) h. Grzymała (1453-1455): Regesta (BS) nr 93, 112; Lib. Ben. III, s. 288.

2 Wacław (Laczlaus) z Jodłownika w pow. szczyrzyckim (1453): Regesta (BS), nr 93.

3 Piotr Rozemberski h. Jastrzębiec (1457-1480): Lib. Ben. I, s. 11; AGZ XI nr 3382, 3492; XVI 178, 1653.

4 Mikołaj Rokosz (Rokoszek) z Koszyc koło Tarnowa 1453: Regesta (BS) nr 93.

5 Piotr Cieśla z Krajowa w opoczyńskiem, kanonik krakowski (1443), kantor wiślicki, pleban w Dzierążni, altarysta Sw. Wawrzyńca w katedrze krakowskiej, zm. w r. 1460: Przybyszewski, Wypisy I, s. 4.

6 Paweł Cząstkowski, kanonik gnieźnieński (1459-1480): Korytkowski, t. I, s. 163. 
Jacobum de Senno prepositum Cracoviensem debitorem principalem et Iohannem Dlugosch custodem Wislicensem et canonicum Cracoviensem pro eo fideiussorem de quadraginta marcis peccuniarium cum effectu per dominum Iohannem iuvenem Dlugosch ${ }^{1}$ canonicum Cracoviensem eorundem dominorum nomine solutis Wenczeslaus alias Waczlaw de Jodlownyk et Nicolaus Rok[osz] de Cosczicze notarius domini castellani Cracoviensis suo ac nobilis Petri de Rozembarg in vim mandati ipsis per eum pridem dati ac filiarum olim nobilis Elwigi de Besdzedza nominibus caventes, de rato ipsorum quittaverunt et absolverunt promittentes et se obligantes ipsos dominos solventes a quibuscumque personis propinquis et extraneis alias ad pecunias huiusmodi se habere qualemcumque propinquitatem asserentibus necnon dampnis et impedimentis evincere, liberare et indempnes reddere ac terminum solucionis triginta marcarum residuarum sub modis et condicionibus superius in obligacione expressis eisdem dominis solventibus ipsi creditores ad festum s. Jacobi proximum indulserunt et prorogaverunt. Presentibus nobili Stanislao de Chrzanow, Nicolao de Luczlawicze, Georgio de Zabno clericis, Nicolao Konwa de Wylkowiska et Nicolao de Mileowicze laico.

Offic. Crac. 9 s. $456-457$.

Johannis Dlugosch canonici Cracoviensis ad replicaciones Stanislaus de Luboradz ${ }^{1}$ nomine magistri Stanislai de Schadek $^{2}$ verbo generaliter contradixit duplicando, in presentia Nicolai de Pyandziczow petentis hincinde interloqui.

Offic. Crac. 7 s. 27.

Johannis Dlugosch plebani in Clobuczsko ad instantem monicionem contra nobilem Georgium burgrabium de Krzepycze emissam dominus in contumaciam eiusdem domini Georgii dicti Komorowski decrevit robur habere et excommunicandum publice in ecclesiis, instante prefato domino Johane Dlugosch.

Offic. Crac. 7 s. 52 .

18

11 II 1455

Nicolaus de Costen ${ }^{1}$ licenciatus in decretis cancellarius Wratislaviensis triginta florenos Hugaricales debiti certi ex causa mutui domino Iohanni Dlugosch custodi Wisliciensi et canonico Cracoviensi ad nunc venturum Pentecostes festum sub excommunicacionis penis solvere obligavit. Presentibus

151 Jan Długosz iunior, brat historyka, notariusz publiczny (1442), pleban w Kłobucku, kanonik katedralny krakowski (1453), zm. w r. 1471: PSB V, s. 180.

161 Stanisław z Luboradza, magister artium Uniwersytetu Krakowskiego (1456): LP, s. 47.

2 Stanisław z Szadka, magister artium Uniwersytetu Krakowskiego (1444). profesor teologii, kanonik Sw. Floriana na Kleparzu: LP, s. 35.

$18{ }^{4}$ Mikołaj z Kościana, doktor dekretów, oficjał i wikariusz generalny poznańśi (1449-1450), zm. w r. 1485, PSB XXI, s. 116-177. 
dominis Raphaele de Skawina ${ }^{2}$ officiali, Mathia de Grodecz et Paulo ${ }^{3}$ in Marciporamba plebano.

Ofic. Crac. 9 s. 777.

Albertus plebanus de Chotel ${ }^{1}$ domino Stanislao Sulkonis plebano in $\mathrm{Ky}$ ge ${ }^{2}$ quattour marcas ad festum Penthecnostes et alias quattour marcas ad festum s. Michaelis, festa immediate sequentia sub pena vallata quinquaginta florenorum iuxta decretum venerabilium dominorum Iacobi de Senno administratoris etc. et magistri Iacobi ${ }^{3}$ canonici Sandomiriensis, amborum dominorum Dlugosch, se solvere obligavit. Presentibus burgrabio de Crzeskouo. Offic. Crac. 9 s. 818.

Ioannes Swydniczar ${ }^{1}$ et Ioannes Theschnar ${ }^{2}$ consules civitatis Cracoviensis nomine domini Georgii Szworcz ${ }^{3}$, decani Sandomiriensis et plebani de sancta Maria in Cracovia ac Ursule, Agnetis, Stanislai ipsius germanorum caventes pro eisdem, ac Ieronimus et Ioannes eciam ipsorum germani suis eorundem nominibus ab una necnon magister Mathias de Sanspow ${ }^{4}$ canonicus s. Floriani in Cleparzs suo et venerabilis domini Iohannis Dlugosch custodis Visliciensis et canonici Cracoviensis cavendo de rato ipsius nominibus et Servacius de Kyelpyny ${ }^{5}$ studens Cracoviensis partibus ex altera, constituti personaliter confessi sunt libere et sponte concordiam inter se fecisse occasione quarundam pecuniarum per olim nobilem Katherinam Stimbarska ${ }^{6}$ in vim contractus empcionis censuum viginti marcarum super quodam orto extra walwam s. Nicolai olim domino Georgio Sworcz ${ }^{7}$ civi et consuli Cracoviensi patri predictorum germanorum datarum sub forma, quod omnes quoscumque contractus empcionis et vendicionis censuum ac notas inscriptiones in actis tam vicariatis quam officialiatus Cracoviensium et ubicumque notatis et scriptas anullando, cassan-

2 Rafal ze Skawiny h. Doliwa, doktor dekretów, prepozyt kielecki, kanonik, oficjał (1440), wikariusz generalny krakowski, pleban u św. Mikołaja w Krakowie do r. 1462, zm. w r. 1469: Przybyszewski, Wypisy I, s. 6.

3 Paweł pleban w Marcyporębie w pow. śląskim (1455): Regesta (BS) nr 111.

191 Chotel Czerwony, pow. wiślicki.

2 Kije, pow. wiślicki.

3 Jakub z Szadka h. Wieniawa, doktor dekretów Uniwersytetu Krakowskiego, kanonik krakowski (1464), sandomierski, kielecki, prepozyt przemyski, wikariusz in spiritualibus generalny krakowski (1476), zm. w r. 1487: PSB X, s. 367-368.

201 Jan Sweidniczer, prawo miejskie przyjął w Krakowie w r. 1428. rajca krakowski (1466-1475). Występuje jeszcze w r. 1481: Cracovia artificum, s. 310.

2 Jan Teszner, syn Jana, mieszczanin i rajca krakowski. (1467-1491): Regesta (BS) nr 114; Kod. UJ III, s. 18; Cracovia artificum, nr 1028, 1093.

3 Jerzy Szwarz (Sworcz) Jurga, syn Jerzego, rajcy krakowskiego, archiprezbiter kościoła NMP w Krakowie (1450-1489): Regesta (BS) nr 99, 100, 1.10, 114; DokKKr II, s. 464.

4 Maciej z Sąspowa, magister artium Uniwersytetu Krakowskiego (1437), doktor teologii (1460), zm. w r. 1472: PSB XIX, s. 36.

5 Serwacy z Kielpin koło Strzyżowa, notariusz (1454): Regesta (BS) nr 100, 114.

; Katarzyna Stimbarska z Krakowa (1446-1455): Regesta (BS) nr 31, 99, 100.

7 Jerzy Szwarz (Sworcz) rajca krakowski. Pochodził z Sącza. Prawo miejskie przyjął w r. 1414. W r. 1442 został wyniesiony do stanu szlacheckiego. Zmarł w r. 1451, zostawiając z pierwszej żony dzieci: Jerzego, Hieronima, Jana, Urszulę i Agnieszkę (żonę Jana Sweidniczera), z drugiej syna Stanisława: Cracovia artificum, nr 1028 (s. 312). 
do, penitus extingwendo et mortificando, in perpetuum tamquam pro principali seu capitali pecunia atque eciam censibus retentis prefati domini Ishannes Swydniczar et Iohannes Theschnar caventes et se principales debitores pro dictis olim domini Georgii Sworcz natis et pueris ponentes, ducentas marca pecuniarum monete communis successive solvere et apud acta domini officialis reponere, videlicet quinquaginta ad sancti Michaelis, quinquaginta ad Nativitatis Ihesu Christi Domini nostri, ad s. Stanislai in Mayo proxime ventura quainquaginta et residuas quinquaginta marcas ád s. Iacobi anni affuturi festa se continue et immediate sequentia aub excommunicacionis penis una cum äiscretis. Ieronimo et Iohanne presentibus manu coniuncta prefatis dominis magistro Mathie de Sanspow, Iohanni Dlugosch canonico Cracoviensi et Servacio de Kyelpyny omnibus simul et coniunctim obligaverunt et submiserunt, hcc tamen adiecto et servato, quod ipsi domini Iohannes Dlugosch, Mathias de Sanspow et Serwacius, antequam pecunias huiusmodi prime rate tollent de sctis domini officialis, faciant primo caucionem ydoneam et suficientem apud acta de idempnitate predictarum Iohannis Swidniczar, Iohannis Theschnar fideiussores et puerorum domini Georgii Sworcz principalium prefatorum ipsosque ab omnibus impedimentis, molestacionibus et perturbacionibus quarumcumque personarum propinquarum vel extranearum dicte Katherine Stimbarska occasione dictarum pecuniarum evincere ac liberos et indempnes reddere; c'e quibusquidem pecuniis, in primis et ante omnia ipse magister Mathias tollet pro se racione expensarum et impensarum sedecim marcas minus septem grossos dicto Servacio consenciente. Presentibus dominis Johanne Iuniore Dlugosch canonico Cracoviensi, Paulo de Gezewo prebendario in Castro S. Trinitatis, magistro Stanislao de Dambycza ${ }^{8}$, Nicolao de Constantin altarista de S. Maria, Iohanne familiari prefati domini Dlugosch et Mathia Clekoth. Offic. Crac. 9 s. $836-837$.

Barthossius alias Barthosch conversus de Przemanczany ${ }^{1}$ occasione decimarum manipularium ibidem viginti marcas communis pecunie venerabilibus viris dominis Iohanni Seniori Dlugosch custodi Wisliciensi et Nicolan de Senno ${ }^{2}$ canonico Cracoviensi, aut alias domino Nicolao Bogdan ${ }^{3}$ vicario Cracoviensi perpetuo ipsorum factori obligavit solvere sub pena excommunicacionis; quarum decem ad Pasce et decem alias marcas ad Penthocostes festa sequencia continue. Presentibus Iohanne Rolya de Wyerzeyky ${ }^{4}$ notario publico et Iohanne Mykanowsky clericis.

Offic. Crac. 9 s. 861. S. 45 .

8 Stanisław z Dębicy, magister artium Uniwersytetu Krakowskiego (1454): LP,

211 Przemęczany, pow. proszowicki. Dziesięciny $\mathrm{z}$ nich należały do prebendy i kanonii więcławskiej, którą posiadał Długosz oraz do kanonii i prebendy bosutowskiej, należącej wówczas do Mikołaja z Sienna: Lib. Ben. I s. $99,35$.

? Mikołaj z Sienna h. Dębno, kanonik krakowski (1444) i gnieźnieński (1455), archidiakon sandomierski i zawichojski, scholastyk wiślicki i łęczycki, zm. w r. 1484: Korytkowski, III, s. 491-492; Przybyszewski, Wypisy I, s. 10.

3 Mikołaj, syn Bogdana $z$ Wawrzeńczyc, student Uniwersytetu Krakowskiego (1440), wikariusz katedralny krakowski (1458-1462): AS, s. 96; Regesta (BS) nr 213; Kod. UJ II, s. 194.

${ }^{4}$ Jan Rola, syn Stefana z Wierzejek, notariusz (1455-1458): Kod. UJ II, s. 161, 
Stanislaus Byeczsky ${ }^{1}$ de Cracovia canonicus s. Georgii in Castro Cracoviensi plebanus in Nyegardow ${ }^{2}$ una cum matre sua recognoscendo se venerabilibus dominis Iohanni Dlugosch custodi Wisliciensi et Iohanni Dlugosch canonicis Cracoviensibus teneri triginta florenos Hungaricales auri puri et iusti ponderis racione mutui, obligaverunt se eosdem triginta florenos in auro prefatis dominis Dlugosch ad festum Pasche proxime affuturum sub pena excommunicacionis solvere nullis excepcionibus ipsos evadendo, et nihilominus in vim pignoris reposuerunt precinctam argenteam deauratam in se auro intextam, quam ipsi domini Dlugosch, interim quo totalem et realem solucionem non habuerint predictorum triginta florenorum, apud se retinebunt. Presentibus Benedicto Tartaro presbitero de Cracovia et Iohanne de Byeszanowo.

Offic. Crac. 9 s. 882.

Magister Johannes de Slupcza ${ }^{1}$ professor sacre theologie et canonicus s. Floriani extra muros Cracovie obligavit se tamquam principalem, quod pro festo s. Stanislai in Mayo solvet undecim cum media marcas et pro festo s. Michaelis proxime venturo alias undecim cum media marcas in manus venerabilium virorum dominorum Jacobi prepositi, Johannis Dlugosch et Rafaelis de Skawina, canonicorum Cracoviensium tamquam coexecutorem testamenti olim reverendissimi in Christo patris domini domini Sbignei ${ }^{2}$ miseracione divina tituli s. Prisce sancte Romane ecclesie presbiteri cardinalis et episcopi Cracoviensis sub pena excommunicacionis. Presentibus ibidem honorabilibus et discretis magistro Jocobo de Szadek et Johanne ${ }^{3}$ plebano de Bodzanczyin.

Offic. Crac. 9 s. 894.

Stanislaus et Procopius, heredes de Lyppye ${ }^{1}$ occasione decime in Krakoschwycze ${ }^{2}$ per ipsos empte domino Johanni seniori Dlugosch ad nunc venturum festum s. Stanislai in Máyo ambo manu coniuncta et in solidum sex cum media marcas communis pecunie sub pena excommunicacionis solvere obligarunt. Presentibus dominis.

Offic. Crac. 9 s. 901.

Martinus Lysz, Petrus Zambkowskowsky et Stanislaus Myedzvyadek cives in Slawkow manu coniuncta et indivisa unus pro altero cavendo obligaverunt

221 Stanisław Biecki z Krakowa, syn Marcina mieszczanina krakowskiego, student Uniwersytetu Krakowskiego (1442): AS, s. 103.

2 Niegardow, pow. proszowicki.

231 Jan ze Słupczy, doktor teologii, kantor u Św. Floriana na Kleparzu (1440). proboszcz u Sw. Mikołaja w Krakowie (1466), kanonik krakowski (1475), zm. w r. 1488: PSB X, s. 476-478.

2 Zbigniew Oleśnicki h. Dębno, biskup krakowski (1423-1455), kardynał (1449): FSB XXIIII, s. $776-781$.

3 Jan, pleban w Bcdzętynie (pow. sandomierski), kustosz skarbu biskupa Oleśnickiego (1455-1465): Regesta (BS) nr 249; Lib. Ben. II, s. 299.

24 Stanisiaw Lipski z. Lipio. (pow. szczyrzycki) h. Drużyna (1446-1480): StPPP VII. nr 837; Lib: Ben. III, s. 278.

2 Kralruszowice, wieś w pow.'szczyrzyckim. 
se venerabili domino Iohanni Dlugosch custodi Wislicensi et canonico Cracoviensi, presente Mythkone familiari suo, septemdecem marcas pecuniarum intuitu XVII bancorum salis aput prefatum dominum custodem empti pro festo s. Stanislai proximo in Mayo sub pena excommunicacionis soluturos. Presentibus magistro Iohanne plebano in Zyelonky ${ }^{\mathbf{1}}$, Iohanne de Coprzywnicza $^{2}$, Stanislao in Slawycze ${ }^{3}$ plebano.

Offic. Crac. 9 s. 902.

Iohannes Dlugossius custos Visliciensis et canonicus Cracoviensis magister Mathias de Sanspow s. Floriani in Cleparzs canonicus et Servacius de Kyelpino factores Katherine Stymbarska et eiusdem testamenti et ultime voluntatis fideicommissarii, receptis quinquaginta marcis peccuniarum a Iohanne Swidniczar et Iohanne Teschnar consulibus Cracoviensibus fideiussoribus pro Georgio Sworcz plebano de S. Maria in Cracovia et ipsius fratribus sororibusque pro festo proxime transacto Nativitatis Christi ad solvendum obligatis, predictos fideiussores et principales quittaverunt et absolverunt de debito huiusmodi, obligantes se ad instanciam quarumcumque personarum dictos fideiussores et principales pro huiusmodi quinquaginta marcis evincere et reddere indempnes. Presentibus Iacobo de Lypino, Cristofero de Mariambork ${ }^{\mathbf{1}}$ clericis.

Offic. Crac. 9 s. 928.

Magnificum dominum Johannem de Czyszow ${ }^{1}$ castellanum et capitaneum Cracouiensem dominus Johannes senior Dlugosch custos Vislicensis et canonicus Cracoviensis procurator reverendi patris domini Jacobi de Senno prepositi Gneznensis Cracoviensis et Scarbimiriensis ecclesiarum eo nomine de trecentis marcis communis pecunie certi debiti in actis presentibus superius obligati, recognoscendo se cum effectu easdem trecentas marcas recepisse et levasse, quittavit et absolvit, liberum et absolutum fecit. Presentibus dominis Johanne Kobylensky ${ }^{2}$, Mathia Opoczka ${ }^{3}$, Vlrico de Cracovia ${ }^{4}$ et Nicolao baccalario notario domini Cracoviensis.

Offic. Crac. 9 s. 930.

25 I Zielonki, wieś w pow. krakowskim.

2 Jan z Koprzywnicy, długoletni prokurator spraw konsystorza krakowskiego, kanonik Sw. Michała na Zamku w Krakowie, zm. w r. 1481: Regesta (BS) nr 196; Przybyszewski, Wypisy I, s. 24.

3 Sławice, wieś w pow. prosžowickim.

$26 \quad 1$ Krzysztof z Malborka, student Uniwersytetu Krakowskiego (1442), bakałarz artium (1455), prawdopodobnie identyczny z pisarzem miejskim w Krakowie, zm. w r. 1481: AS, s. 102; LP, s. 37; Cracovia artificum, s. 311.

271 Jan z Czyżowa h. Półkozic, wojewoda (1437-1438), kasztẹlan (1438-1458) i starosta krakowski (1440-1457): Fedorowicz, s. 264.

2 Jan Kobylański z Kobylan h. Grzymała, stolnik krakowski, starosta brzeski (1454), zm. w r. 1471: Regesta (BS) nr 124; PSB XIII, s. 162-163:

3 Maciej Opoczka, wójt krakowski (1446-1473): Księgi przyjęć do prawa miejskiego w Krakowie. Wyd. K. Kaczmarczyk, Kraków 1913, nr 5636, 6277, 7391; Cracovia artificum nr 614; Kod. UJ II, s. 132, 133, 236.

4 Może Ulrych, syn Zygmunta z Krakowa, student UUniwersytetu Krakowskiego (1448), bakałarz dekretów i pleban w Giebultowie: AS, s. 118; Regesta (BS), nr 115. 
Jacobus nobilis Obulecz de Gory ${ }^{1}$ quatuor cum media marcas occasione decime in Byalecz ${ }^{2}$ per patrem suum empte venerabili domino Johanni Dlugosch custodi Visliciensi et canonico Cracouiensi sub excommunicacionis pena solvere obligavit infra hinc ad festum s. Stanislai in autumpno proxime venturum. Presentibus Virico clerico de Cracovia et Petro alias Pyethrzik ${ }^{8}$.

Offic. Crac. 9 s. 247.

\section{9}

16 III 1456

Johannes Dlugosch custos Visliciensis et canonicus Cracoviensis ecclesiarum, receptis viginti marcis peccuniarum a nobili Nicolao Czykowsky ${ }^{1}$ de Mykluschovicze septuaginta marcarum et XX scotorum extremi et finalis debiti ad acta presencia obligat domino olim Sbigneo cardinali et episcopo Cracoviensi per olim dominum Petrum Czykowsky ${ }^{2}$ patrem dicti Nicolai debiti, pro quo alias generosi domini Rokcssius ${ }^{3}$ burgrabius castri Cracoviensis et Sdebor de Swyradzicze ${ }^{4}$ fideiussores existerunt, predictum Nicolaum suo et aliorum coexecutorum nominibus liberum misit et quitat et adhuc dictus Nicolaus $\mathrm{C}_{z y}-$ kowsky quinquaginta marcas cum XX scotis solvere tenebitur.

Offic. Crac. 9 s. 949.

Nicolaus Synovyecz de Zandouicze ${ }^{1}$ principalis debitor et Petrus Dunyn de Moravyany ${ }^{2}$ pro eo fideiussor et se ponendo principalem, ambo manu coniuncta et in solidum obligaverunt se venerabili domino Jacobo de Senno preposito Cracoviensis et Scarbimiriensis ecclesiarum decem marcas aut alias, quantum in actis olim reverendi patris domini Sbignei cardinalis et episcopi Cracoviensis apparebit contineri, ad festum sancti Michaelis proximum sub pena excommunicacionis solutoros; et in continenti Nicolaus Raczko prefatos Synovyecz et Dunin nobiles monuit, ut infra hinc et festum s. Michaelis predictum et ipsius octavas dictum debitum domino Jacobo preposito prefato exsolverent, alias prima die iuris inuente sequente post ipsas octavas comparerent ad videndum et audiendum se excommunicacionis sentencias incidisse

281 Jakub Obulec z Gór i Bronocic h. Odrowąż, syn Bartosza Obulca z Gór. podczaszy krakowski, starosta czorsztyński (1462), zm. w r. 1467: PSB XXIII, s. $481-482$.

2 Prawdopodobnie Bilczów (pow. wiślicki), wieś Obulców, z której dziesięcina należała do kustodii wiślickiej: Mat. PSH-G PAN.

3 Piotr Pietrzyk z Kęt, wikariusz katedralny krakowski (1443), proboszcz w Dębicy (1471): Regesta (BS) nr 115, 331; DokKKr II, s. 413.

291 Mikołaj Cikowski z Mikluszowic i Dziewina, sędzia grodzki krakowski (1452-1457): Regesta (BS) nr 115, 130; Fedorowicz, s. 264.

2 Piotr Cikowski, podsędek generalski ziemski krakowski (1442-1454), sędzia (1454): T. Fedorowicz, s. $68-70$.

3 Jan Rokosz, burgrabia krakowski (1445-1457), sędzia generalny ziemski krakowski (1455-1464): Fedorowicz, s. 279.

4 Zdziebor ze Swiradzic (Sieradzic w pow. proszowickim) h. Zabawa: Lib. Ben. I, s. 131

301 Mikołaj Synowiec z Sędowic (pow. ksiąski), burgrabia krakowski (1437-1461): Fedorowicz, s. 284.

2 Piotr Dunin z Prawkowic i Morawian, burgrabia krakowski (1459), marszałek nadworny i podkomorzy sandomierski (1460), wojewoda brzesko-kujawski (1480), zm. w r. 1484: PSB V, s. 479. 
declarari; et in vim hanc prefatus dominus prepositus et venerabilis dominus Johannes Dlugosch executores testamenti olim domini cardinalis et episcopi Cracoviensis predicto domino Nicolao Synovyecz in absolucionem consenserunt. Presentibus Nicolao de Lomza et Nicolao de Drochlin familiaribus eiusdem domini prepositi.

Offic. Crac. 9 s. $952-953$.

Georgium Schworcz plebanum de S. Maria, Ieronimum, Johannem et Ursulam ipsorum sororem nec non Johannem Swyeydniczar et Johannem Teschnar ipsorum fideiussores ac tamquam principales omnes in solidum venerabilis et honorabilis domini Johannes Iunior Dlugosch nomine domini Johannis Dlugosch fratris sui senioris et cavendo de rata ipsius magister Mathias de Sanspow factores testamenti olim Katherine Sthimbarska et discretus Servacius de Kyelpini nepos eiusdem Katherine, omnes in solidum de saxaginta sex marcis pecuniarum iuxta superius scriptam obligacionem, recognoscendo se eosdem cum effectu recepisse et solucionem totalem habuisse, quittaverunt quittatosque é solutos fecerunt cum effectu et in continenti prefatus magister Mathias modo et forma meliori dictum Servacium de decem cum sex marcis sibi cum effectu solutis similiter quittavit et liberum dimisit. Presentibus dominis Mathia altarista et vicario castri Cracoviensis, Bernhardo Pauli de Myanow ${ }^{1}$, magistro Stanislao de Dambicza et Cristoforo ${ }^{2}$, clerico domini Dlugosch et aliis pluribus.

Offic. Crac. 9 s. 991.

Johansis Dlugosch senioris ex una, et ex adverso Laurencii Marci de Pobrzesze ex alia partibus, in causa ad idem faciendum ad VIII [diem] terminus continuatur de consensu domini Johannis Dlugosch Iunioris et prefati Laurencii. Presentibus [quibus] supra.

Offic. Crac. 7 s. 557.

Magister de Sanspow Johannes Dlugosch senior canonicus Cracoviensis, factores olim Katherine Stimbarska et Servacius de Kyelpino nepos eiusdem Katherine publice et expresse recognoscentes pueros olim Georgii Sworcz civis Cracoviensis occasione quinquaginta marcarum pro ultima ratha ipsi Servacio obligatarum et per ipsum effectualiter levatarum et receptarum et fideiussores eorundem puerorum, videlicet Johannem Swyndniczar et Johannem Thesnar, quitaverunt liberosque et paccatos pretextu huiusmodi quinquaginta marcarum ipsi Servacio obligatarum miserunt. Prefatus eciam Servacius, huiusmodi peccuniis ultime solucionis receptis, promisit et se obligavit prefatos dominos Johannem Dlugossium canonicum, magistrum Mathiam Sanspowski tanquam factores ac pueros ipsius olim Georgi Sworcz quoquo modo nominatos et fideiussores eorum pro omnibus impedimentis indempnitatis ad instanciam qua-

311 Bernard, syn Pawła z Mianowa, notariusz, altarysta i wikariusz katedralny krakowski, pleban w Raciborowicach. Występuje w latach 1448-1481: Regesta (BS) nr 251; DokKKr II, s. 548; Cracovia artificum, nr 812.

2 Krzysztof prawdopodobnie z Dębowca, notariusz Długosza, wikariusz i altarysta katedralny krakowski (1481-1482): Przybyszewski, Wypisy I, s. 66. 
rumcumque personarum, presertim ipsius consanguineorum reddere indempnes et evincere, quociens opus occurrerit. Presentibus magistro Stanislao de Luboradz, Mithkone et Leonardo ${ }^{1}$ familiaribus domini Dlugoschi et Bernardo de Myanov notario.

Offic. Crac. 9 s. 1021.

34

5 I 1457

Katherina Byaluschina ${ }^{1}$ relicta olim magnifici domini Nicolai Byalucha castellani Cracoviensis ponendo se principalem pro Petro Kytha kmethone tunc de Bolechowicze ${ }^{2}$ obligavit se venerabili domino Johénni Dlugosch seniori canonico tres marcas cum viginti grossis peccuniarum pro festo Nativitatis Sancte Marie proximo sub pena excommunicacionis soluturam. Pro residuo vero debito ipse Kytha prefato domino Dlugossio in hereditate in Bolechowicze caucionem fideiussoriam facturus est. Presentibus laicis de Lubocza ${ }^{2}$.

Offic. Crac. 10 s. $19-20$.

Johannis senioris Dlugosch canonici Cracoviensis ad libellum magister Stanislaus de Grab[owa] ${ }^{1}$ nomine Stanislai de Gonow ${ }^{2}$ animo et intencione littem legittime contestando negavit narrata prout narrantur etc.; presente Petro de Glolgovia] ${ }^{3}$ ad feriam secundam proximam articulabit.

Offic. Crac. 7 s. 728 .

36

12 II 1457

Nicolaus Zarogowski ${ }^{1}$ nobilis et civis Cracoviensis et Katherina consors eius ambo manu coniuncta et indivisa centum florenos Vngaricales puri auri et iusti ponderis occasione certi debiti mutui ad festum s. Viti proxime venturum venerabilibus dominis Johanni Dlugosch seniori et Johanni Dlugosch iuniori canonicis Cràcoviensibus sub excommunicacionis pena solvere cbligarunt. Presentibus nobili domino Johanne Kobylensky, Cristoforo de Marienborg, Johanne pictore de Cracovia ${ }^{2}$.

Offic. Crac. 10 s. 43.

331 Leonard prawdopodobnie z Woli, domownik Dlugosza (1456-1458): Regesta (BS) $n r 115$.

341 Katarzyna, córka Spytka z Melsztyna, żona księcia mazowieckiego Janusza (1408), pctem drusa żona Mikołaja z Michałowa, zwanego Białucha, fundatorka kolegiaty dla Koliegium Mniejszego Uniwersytetu Krakowskiego. Zmarla prawdopodobnie w r. 1456: PSB XXI, s. 125.

2 Bolechowice i Lubocza, wsie w pow. krakowskim.

351 Stanisław z Grabowej, prokurator konsystorza krakowskiego (1441): Cracovia artificum, nr $366,372,374$.

2 Zob. niżej nr 39. Może to Stanisław Sikora, soltys w Gunowie (1440-1446): Mat. PSH-G PAN.

3 Piotr z Głogowa, prokurator konsystorza krakowskiego (1465-1471): Kod. UJ II, s. 240 , III, s. 36.

361 Mikołaj Zarogowski z Krakowa (1439-1486): Regesta (BS) nr 94 (dodatek) Słownik historyczno-geograficzny województwa krakowskiego w średniowieczu, cz. 1, Wrockaw 1980, s. 92-93.

: Jan, malarz z Krakowa, może z Leśnej koło Bodzętyna (1453-1488): Przybyszewski,W ypisy I, s. 19. 
Sdeborius heres de Swyradzice recognoscendo se teneri et obligatum esse quinquaginta marcas pecuniarum debiti olim reverendissimi in Christo patris domini Sbignei cardinalis et episcopi Cracoviensis in actis superius presentibus, eademque obligacione priori cassata prefatas quinquaginta marcas ad festum s. Stanislai in Maio a festo proximo venturo sancti Stanislai ad aliud tunc sequens festum s. Stanislai domino Johanni Seniori Dlugosch tamquam executori testamenti predicti domini cardinalis sub pena excommunicacionis solvere obligavit. Presentibus notariis.

Offic. Crac. 10 s. 47.

Nicolaus Spiczmeri de Cracovia decretorum doctor cantor Cracoviensis etc. cassando, anulando et mortificando in eternum obligacionem superius de ducentis florenis Hungaricalibus domino Jacobo de Senno protonotario apostolico et preposito Cracoviensi etc. factam ac pro festo Nativitatis Christi proxime preterito solvi debitos, eosdem ducentos florenos Hungaricales per presens expressos prefato domino Jacobo de Senno preposito etc. ad festum Nativitatis Christi proxime venturum sub censuris ecclesiasticis obligavit soluturum. Presentibus venerabili domino Johanne seniore Dlugosch tamquam factore et procuratore dicti domini prepositi huiusmodi obligacionem nomine suo recipiente et admittente, Johanne de Schebnya ${ }^{1}$ plebano in Skalka, Bernardo de Myanow notariis.

Offic. Crac. 10 s. 48.

Johannis senioris Dlugosch canonici nomine magister Petrus de Glogouia libellum loco posicionum et articulorum contra Stanislaum scoltetum de Gonow verbo repetit. Presente dicto Stanislao, qui ad omnes tanquam ad articulos respondit per verbum: non credit. Presente Petro de Glogovia, qui post festa tempore suo probabit. Presentibus supra.

Offic. Crac. 7 s. 799.

Nicolaus Czikowsky heres de Czikowycze filius olim domini Petri Czikowsky iudicis terre Cracoviensis et successor in bona derelicta parendoque obligacioni per prefatum suum patrem tamquam principalem necnon dominos Johannem Rokos et Sdeborium de Swyradzicze pro eo fideiussores de ducentis marcis cum XXti marcis reverendissimo olim domino Sbigneo cardinali et episcopo Cracoviensi facte viginti marcas residuas dicti debiti in vim totalis solucionis domino Johanni Seniori Dlugosch canonico Cracoviensi tanquam executori testamenti prefati olim domini cardinalis solvit, liberando prefatos sui patris fideiussores et se ipsum. Quemquidem Nicolaum Czikowsky nobiles necnon prefatos fideiussores ipsius prefatus dominus Johannes Dlugosch cum domino Raphaele officiale ut executore suo et suorum coexecutorum, videlicet

381 Jan Skałka ze Szebni (Szebieński), syn Henryka h. Biberstein, pleban na Skałce na Kazimierzu w Krakowie, kanonik krakowski (1472), kustosz katedralny (1482), zm. w r. 1499: Przybyszewski, Wypisy I, s. 29. 
Cracoviensis et Sandomiriensis pallatinorum et domini prepositi Cracoviensis ${ }^{1}$, nominibus receptis prefatis viginti marcis ac recognoscendo se iam totalem solucionem habuisse et cum effectu ab ipso domino Nicolao recepisse, cassando iam et in eternum mortificando omnes inscripciones et obligaciones tam per ipsum dominum Nicolaum quam eiusdem patrem ad dictos pro ipsis ficieiussores factas quittavit, absolvit liberosque et absolutos fecit. Presentibus dominis Johanne Iuniore Dlugosch, Bartholomeo plebano in Pelcziska ${ }^{2}$ et Ulrico altarista in ecclesia Cracoviensi.

Offic. Crac. 10 s. $162-163$.

Venerabilis domini Johannis Dlugosii senioris etc. executoris olim reverendissimi in Christo Patris et domini Sbignei miseracione Divina etc. s. Prisce s. Romane ecclesie presbiteri cardinalis et episcopi Cracoviensis ex una et domine Dore ${ }^{1}$ de Cracovià partibus ab altera in causa, idem dominus Dlugossius petivit iuxta exigenciam termini pignora, ut dicebat, in triginta florenis olim prefato domino cardinali in humanis tunc agente et per ipsum impignorata redimi alias distrahenda decerni, magistro Stanislao de Damb[icza ${ }^{2}$ ex adverso ipsius Dore procuratore super ipsis pignoribus in eundem dominum Dlugossium prout executorem huiusmodi agere non posse, cum non ipsi olim domino cardinali, sed domino Johanni de Bodzanczin plebano fuerunt et sunt per eam in certa summa impignorata et non solum duo, sed tres cinguli, petens ob hoc ab instantia domini Dlugosii partem suam absolvi. Et dominus, hiis attentis, accionem sibi domino Johanni, cum hic advenerit, et per eum sibi domino Johanni per ipsam Doram decrevit. Presentibus dominis Venceslao plebano de Zalesche et Vlrico de Cracovia baccalario in iure et aliis multis.

Offic. Crac. 7 s. 963.

42

19 XII 1457

Executorum testamenti olim domini Sbignei cardinalis et episcopi Cracoviensis ad instanciam Michael de $\operatorname{Wartha}^{1}$ citavit ad hanc horam terciarum presentis diei magistrum Johannem de Coprzywnicza tanquam procuratorem nobilium Pauli Oppalacz de Woyslawycze ${ }^{2}$ et Spithkonis de Coczonow ${ }^{3}$ ad videndum ipsos dominos executores surrogari in ius et debita olim domini Nicolai plebani in Antiqua Brzesko, in quibus dicti nobiles prefato olim domino Nicolao fuerunt et sunt obligati, et incontinenti dominus Johannes Iunior Dlugosch procurator et eo nomine dictorum dominorum executorum, allegando

401 Wykonawcami testamentu Zbigniewa Oleśnickiego byli poza Długoszem, wojewoda krakowski Jan z Tęczyna, wojewoda sandomierski Jan Głowacz z Oleśnicy i prepozyt krakowski Jakub z Sienna.

2 Pelczyska, wieś w pow. wielickim.

411 Dora, kupcowa z Krakowa (1483-1486): Słownik staropolskich nazw osobowych, t. 1, Wrocław 1965-1967, s. 512.

2 Stanisław z Dębicy, bakałarz artium Uniwersytetu Krakowskiego (1449), magister (1454): LP, s. $41,45$.

421 Michał z Warty, student Uniwersytetu Krakowskiego (1448), bakałarz dekretów (1457), pleban w Minodze: LP, s. 40; rkps BJ 359.

2 Paweł Opalacz z Wojsławic Grzymalita (1423-1441): StPPP II, $\mathrm{nr} 2199,2450$, 2979; Mat. PSH-G PAAN.

3 Spytko z Koczanowa (1447-1457) posiadał patronat kościoła. w Brzesku Starym, w pow. proszowickim: Mat. PSH-G PN. 
prefatum olim Nicolaum plebanum prefato olim domino cardinali et alias executoribus prefatis debitum et obligatum esse in septingentis marcis, quibus non solutis de hac luce decessit, petivit se et alias ipsos dominos executores in ius et debita surrogari et reponi, presente Johanne de Coprzywnicza allegante non debere surrogari, nisi ante omnia constiterit de execucione testamenti prefati. Et dominus inquisitum si est testamentum ipsos dominos executores in persona procuratoris predicti surrogat, de quo testamento prima die iuris post octavas Epiphaniarum Domni ipsi domini executores probabunt. Presente Johanne de Coprzywnicza.

Offic. Crac. 7 s. 964.

Nicolaus de Slona presentatus per certos nobiles ad ecclesiam in Antiqua Brzesko, cavendo et se principalem debitorem ponendo pro nobili Spithkone Coczonow eiusdem ecclesie patrono et collatore, octo marcas pecuniarum per dominum Spiţonem olim domino Nicolao in Antiqua Brzesko plebano nuper defuncto et pro cuibus octo marcis ipse Spithko excommunicabatur, aggravatur et reaggravatur, superreagravatur ad instanciam eiusảem domini Nicolai venerabili domino Johanni seniori Dlugosch executori testamenti olim reverendissimi domini cardinalis episcopi Cracovensis ad festum sancti Miartini proxime venturum sub eisdem sentenciis, quibus ipse Spithko patronus ad instanciam prefati domini plebani extitit innodatus, obligat soluturum et in vim predicte prefatus dominus Johannes Dlugosch dicto Spithkoni consensit in absolucionem, quam ipse Nicolaus factum huiusmodi solicitando per se sibi expedivit et obtinuit, ipseque Spithko reddendo indempnem predictum Nicolaum suum fideiussorem obligavit se similiter sub predictis processibus dictas octo marcas ad prefatum tempus sibi Nicolao fideiussori soluturum et daturum. Presentibus dominis Bernardo de Myanow, Alberto Tribala (?) de Solyecz ${ }^{1}$, Swantoslao plebano in Slauicze.

Offic. Crac. 10 s. 222.

Stanislaus de Slauouicze kmetho dictus Machonyecz quatuor marcas communis pecunie, quas tenebatur olim domino Nicolao plebano in Brzesko, domino Johanni seniori Dlugosch custodi Visliciensi et canonico Cracoviensi tanquam executori olim reverendissimi domini cardinalis, ad festum s. Michealis proximum sub excommunicacionis pena solvere obligavit. Presentibus notariis.

Offic. Crac. 10 s. 228.

45

25 II 1458

Andres Thrzewlinsky ${ }^{1}$ heres de Thrzewlin $^{2}$ cavendo et se principalem debitorem ponendo pro nobili domino Jacobo Dambyensky ${ }^{\mathbf{3}}$ subpincerna $\mathrm{Craco-}$

431 Wojciech z Solca (Solecki), psałterzysta i wikariusz katedralny krakowski, plaban w Mirzcu, prebendarz Sw. Jakuba na Kazimierzu w Krakowie, notariusz oficjała krakowskiego Stanisława Swiradzkiego. W r. 1495 już nie żył: Przybyszewski,Wypisy I, s. 98.

451 Andrzej Trzewliński, dziedzic Wielkiej Wsi(1450-1462): Mat. PSH-G PAN.

2 Trzewlin, nieistniejący obecnie zamek na terenie Wielkiej Wsi pod Wojniczem.

3 Jakub z.Dębna h. Odrowąż, podczaszy krakowski (1448-1460), kanclerz koronny (1469-1473), wojewoda sandomierski (1473-1478), kasztelan krakowski (1478-1490): PSB V, s. $71-73$. 
viensi trecentos florenos Hungaricales certi debiti mutui venerabilibus dominis Johanni seniori et Johanni iuniori Dlugosch canonicis Cracoviensibus successive, videlicet ad quodlibet festum Nativitatis Christi per centum florenos, incipiendo solucionem ad festum Nativitatis Christi proximum et usque ad totalem solucionem eorundem trecentorum florenorum sub pena excommunicacionis obligavit soluturum. Presentibus Stanislao de Rathnya notario publico et aliis pluribus.

Offic. Crac. 10 s. 241.

46

11 III 1458

Nicolaus Pellifex et civis dictus Skamsky tres florenos ocassione certi debiti infra hinc ad festum s. Michealis proxime venturum venerabili domino Johanni Dlugossio seniori canonico ecclesie Cracoviensis sub pena excommunicacionis solvere obligavit. Presentibus ut supra.

Offic. Crac. 10 s. 258.

47

9 IV 1458

Stanislaus Stimbach et Margaretha sua consors legittima de Cracovia ambo manu coniuncta et indivisa, unus pro alio cavendo et se principales ponendo, centum florenos Hungaricales puri auri et iusti ponderis certi debiti mutui et Margaretha prefata preter dictum Stanislaum virum suum sola pro se et ipsius dumtaxat nomine quinquaginta florenos Hungaricales eciam certi debiti mutui a festo sancti Stanislai in Maio anni currentis ad aliud festum s. Stanislai in Maio extunc proxime venturum anni futuri et immediate sequentis venerabili domino Johanni Dlugosch seniori custodi Visliciensi et canonico Cracoviensi sub censuris ecclesiasticis se solvere obligarunt et obligavit. Casu vero, quo aliquid humanitus in ipso Stanislao et Margaretha sua consorte acciderit, extunc in suis omnibus rebus mobilibus et immobilibusque bonis prefatam summam florenorum demonstraverunt repetendam et demonstravit investigandam et recipiendam. Et casu, quo aliquid in ipso domino Johanne Dlugosch seniore acciderit, extunc venerabili domino Johanni iuniore fratri suo germano canonico Cracoviensi prefatam summam centum et quinquaginta florenorum demonstravit repetendam et recipiendam processusque occasione eorundem fulminandos et de eisdem quittandos. Presentibus venerabili domino magistro Paulo de Zathor ${ }^{1}$ canonico Cracoviensi, Johanne Myethnyow, Martino de Mikulicze, Leonardo de Volya, familiaribus domini Dlugosii (na marg.:) Anno 1467 die Veneris XXIIII May venerabilis dominus Johannes Dlugosch senior aput acta presencia coram domino personaliter constitutus [...] consciencia. sua ipsa clarificando retulit et confessus est debitum hic obligatum non fuisse suum, sed olim magistri Pauli de Zathor canonici etc. defuncti, sibi de consensu ipsius magistri Pauli tunc tamquam executori et factori obligatum, nunc autem illud per se aliis occupatus et intervenientibus negociis repetere non valens, totum ius et proprietatem ipsius obligacionis in venerabiles domi-

471 Paweł z Zatora, doktor dekretów Uniwersytetu Krakowskiego, kanonik krakowski i kaznodzieja katedralny, pleban w Raciborowicach, wikariusz generalny krakowski in spiritualibus, zm. w r. 1463: Przybyszewski, Wypisy I, s. 4. 
nos Johannem de Reschow ${ }^{2}$ et Mathiam de Blandow ${ }^{3}$ canonicos etc. ipsius magistri Pauli executores et factores modernos transtulit...

Offic. Crac. 10 s. 280.

48

21 IV 1458

Albertus de Chotel plebanus viginti et novem marcas comunis pecunie ocasione certi debiti mutui recognovit se teneri, quarum decem ad Purificacionis s. Marie anni proxime venturi et alias decem marcas CCCCLX et residuum, scilicet novem marcas, anni tercii proxime venturi, venerabili domino Iohanni Dlugosch Seniori canonico ecclesie Cracoviensis sub pena excommunicacionis solvere obligavit. Presentibus dominis Iuniore Dlugossio canonico Cracoviensi et Michaele Choczna (?) canonico Sandomiriensi.

Offic. Crac. 10 s. 228.

49

30 IX 1458

Zegota ${ }^{1}$ nobilis de Czyrnyechow ex concordia inter ipsum ab una et dominum Iohannem vicarium de Morawicza $^{2}$ super quibusdam maxillacionibus, percussionibus et differenciis factis ab altera partibus, in causa per dominos Iohannem Dlugosch seniorem, Albertum de Lyssecz ${ }^{3}$, Andream de Costen ${ }^{4}$ et prebendarium Krassowsky arbitros et arbitratores et amicabiles compositores infra hinc ad duas septimanas post festum s. Martini proxime venturum eidem domino Iohanni ipse dominus Zegotha sub pena excommunicacionis solvere obligat, hanc ipsam concordiam hincinde sub vadio mille florenorum amplectendo. Presentibus dominis Nicolao de Radom ${ }^{5}$ arcium baccalario et aliis multis circa premissa in Collegio Iuristarum in stuba communi hora vesperarum.

Offic. Crac. 10 s. 349.

Hincza de Rogow ${ }^{1}$ castellanus Siradensis et Regni Polonie vicethezaurarius sponte et libere constitutus, animi sui deliberacione sufficienti prehabita, recognovit et per expressum confessus est se teneri et debitum esse tricentas marcas comunis pecunie monete et numeri Polonicalium comuniter in Regno Po-

2 Jan z Rzeszowa, kanonik krakowski (1456), scholastyk sandomierski, skalbmierski i przemyski, podskarbi królewski, biskup krakowski (1472-1488): Przybyszewski, Wypisy I, s. 15.

3 Maciej z Błędowa (Błędowski) h. Półkozic, doktor dekretów, kanonik krakowski (1463) i sandomierski, kantor przemyski, pleban w Błędowie i Wieliczce, wikariusz in spiritualibus krakowski (1471-1474), zm. w r. 1480: Przybyszewski, Wypisy I, s. 27.

491 Żegota Obrycht z Czernichowa h. Topór (1443-1463). W r. 1468 już nie żyl: Mat. PSH-G PAN.

2 Morawica, wieś w pow. krakowskim.

3 Wojciech Lisiecki z Liśca (de Lyssyecz), magister artium Uniwersytetu Krakowskiego (1438), doktor dekretów, kanonik gnieźnieński (1460), zm. W r. 1468: LP s. 26,30 ; Korytkowski, II, s. $476-477$.

4 Andrzej z Kościana zw. Ruczel, bakałarz artium (1445), magister (1449): Historia nauki polskiej, t. 6, Wrocław 1974, s. 577.

"Mikolaj z Radomia, magister artium Uniwersytetu Krakowskiego (1458): LP, s. 47,52 .

501 Hincza starszy z Rogowa h. Działosza, podskarbi Królestwa Polskiego (1448-1460), kasztelan rozpierski (1443-1453), kasztelan sandomierski (1461-1472): Przybyszewski, Wypisy I, s. 13. 
lonie decurrentis debiti residui occasione villarum Popow et Rambyelycze ${ }^{2}$ per ipsum emptarum venerabilibus viris dominis Johanni seniori custodi Visliciensi et Iohanni iuniori Dlugosch canonici Cracoviensi, fratribus germanis. Quasquidem tricentas marcas eisdem dominis canonicis ad festum Nativitatis Christi anni proximi affuturi videlicet millesimi CCCCLIX se et casu, quo in eo interim aliquid humanitus acciderit, suos legitimos successores sub pena excommunicacionis, monicione dumtaxat unius mensis spacio publice in ecclesia Cracoviensi maiori premittenda, obligavit et submisit daturum et soluturum, renunciando omnibus excepcionibus, appellacionibus, allegacione, expedicione belli, litteris regalibus et aliis quibusvis remediis tam iuris quam facti dilacionem solucionis importantibus. Presentibus dominis Luthkone de Thokary ${ }^{3}$ scolastico Sandomiriensi et canonico Cracoviensi, Iohanne Przeborowsky, Unikone de Cracovia.

Offic. Crac. 10 s. 389

Nicolaus Ruczski de Rudze decem marcas communis peccunie ex causa certi debiti mutui infra hinc et duas dominicas post festum Circumcisionis Domini proxime venturum venerabili domino Iohanni Dlugosch sub pena excommunicacionis se obligavit soluturum. Presentibus dominis Alberto Soleczki, Stanislao Xonski, Martino de Padyanicze, Iohanne Hajdzkone de Swiradzicze ${ }^{1}$ notariis publicis ad premissa testibus.

Offic. Crac. 10 s. 391.

52

25 II 1459

Ego Nicolaus Grzymala de Szwyerzynyam ${ }^{1}$ iudex castri Cracoviensis recognosco me recepisse decem marcas comunis monete numeri Polonicalis consveti a venerabili viro domini Raphaele de Skawina preposito Kyelczensi cananico et officiali Cracoviensi de centum marcis olim reverendissimi domini Sbignei cardinalis et episcopi Cracoviensis aput ipsum respositis de mandato dominorum magnifici Iohannis pallatini Sandomiriensis necnon venerabilium dominorum Iacobi de Syenno prepositi Cracoviesis et Iohannis Dlugossi senioris custodis Wisliciensis canonici Cracoviensis executorum testamenti domini cardinalis prefati. Presentibus Iohanne Rolya de Wyerzeyky, Iohanne Jaszdek de Swyradzycze, Petro de Grzybow.

Offic. Crac. 10 s. $435-436$.

53

31 VII 1459

Jacobus de Senno Sedis Apostolice prothonotarius Gneznensis et Cracoviensis prepositus recognoscendo se in mutuum recepisse et mutuasse mille

-Wsi Popów i Rębielice Królewskie koło Kłobucka. Hincza z Rogowa, zamieniając kościół parafialny w Krzepicach na klasztorny, nadał czynsz z Popowa i Rębielic: Lib. Ben. II, s. 212.

s Lutko z Tokar, prokurator generalny krakowski (1440-1441) podskarbi królewski (1444-1455), kanonik krakowski (1456-1466), scholastyk sandomierski: Fedorowicz, s, 286; Przybyszewski, Wypisy I, s. 11.

51 Jan Jazdek ze Swiradzic (Sieradzic, Swiradzki), student Uniwersytetu Krakowskiego (1459-1466): AS, s. 160; StPPP II nr 3818

521 Mikołaj Grzymała ze Zwierzyńca (z Tczycy, pow. ksiąski), sędzia grodzki krakowski (1458-1461), sędzia dworski królewski (1463-1473), zm. przed r. 1483: Fedorowicz, s. 268. 
florenos Hungaricales auri puri iustique ponderis apud venerabiles dominos Iohannem Dlugosch seniorem et Iohannem Dlugosch iuníorem canonicos Cracovienses, quos quidem mille florenos prefatis dominis Iohanni seniori et iuniori Dlugosch ambobus in solidum obligavit et summisit se soluturum, cum per eosdem dominos canonicos fuerit requisitus et monitus; casu autem quo in prefato domino Jacobo preposito aliquid humanitus acciderit, extunc in et super omnibus et singulis suis bonis mobilibus et immobilibus tam hereditariis quam eciam ecclesiasticis et spiritualibus, quibuscumque nominibus censeantur, commisit et demonstravit repetendum et investigandum prefatum debitum mille florenorum ipsis dominis creditoribus in forma meliori.

Offic. Crac. 10 s. 523.

Iacobus Parthila, Nicolaus Byenyek, Iohannes Parthila kmetones de Zasczytow ${ }^{1}$ omnes manu coniuncta et indivisa unus pro alio caventes et se principalem debitorem ponentes octo marcas communis pecunie occasione decime per ipsos in Glupczow ${ }^{2}$ empte venerabili domino Iohanni seniori Dlugossch canonico ecclesie Cracoviensis infra hinc ad festum Pasche Domini proxime venturum sub pena excomunicacionis solvere obligaverunt. Presentibus dominis Bernardo Pauli de Myanow, Stanislao Grodeczski ${ }^{3}$ notariis.

Offic. Crac. 10 s. 560.

Christoferus Italicus de Sancto Romulo ${ }^{1}$ zupparius Drohobiczensis et theoloneator Leopoliensis recognoscendo se obligari centum et quinquaginta marcas racione debiti mutui venerabilibus viris dominis Iohanni seniori et Iohanni iuniori Dlugosch canonicis ecclesie Cracoviensis, obligavit se et suos successores dictas centum et quinquaginta marcas pro festo s. Katherine hinc per annum proxime affuturo in pecuniis comuniter in regno currentibus vel in mercibus iuxta comunem cursum et forum inter mercatores tunc existencia sub pena excomunicacionis solvere; constituens procuratores videlicet venerabiles dominos Iohannem Rzeszowsky Cracoviensem, magistros Stanislaum de Schamotuli ${ }^{2}$ et Iohannem de Wyelun ${ }^{3}$ canonicos Leopolienses, Mathiam Nicolay de Sandecz, canonicum Sandeczensem, Ulricum in decretis baccalarium et Iohannem de Koprziwnicza absentes omnes et quemlibet eorum in solidum ad recognoscendum huiusmodi debitum et ad suscipiendum in se sentencias excommunicacionis eciam interdicti, ut in forma meliori. Presentibus ibidem discretis et nobilibus dominis Johanne de Baranow notario publico, Nicolao prefati domini Christofori nobili-

541 Zastów (Zaszczytów), wieś w pow. krakowskim.

2 Głupczów, wieś w pow. proszowickim; dziesięcina należała do prebendy więckowskiej: Lib. Ben. I, s. 100.

3 Stanisław Grodecki (z Grodka), notariusz, pleban w Szebriach (1464-1498): Kod. Wiel., s. 36; Inc. BJ 1490.

551 Krzysztof de Sancto Romulo, Włoch, żupnik przemyski (1456-1457): Fedorowicz, s. 228 .

2 Stanisław z Szamotul, magister artium Uniwersytetu Krakowskiego (1444): LP, s. 35.

3 Może Jan Czelp z Wielunia, dziekan wydziału artium Uniwersytetu Krakowskiego (1429): LP, s. 21. 
bus, Nicolao de Brody, Nicolao alias Mythko, Alberto et Stanislao familiaribus dominorum prefatorum senioris et iunioris Dlugosch etc. testibus ad premissa.

Offic. Crac. 12 s. 212.

Andreas nobilis de Krolewycze dyocesis Premisliensis parendo concordie inter ipsum et honorabilem Iohannem de Stobnycza fratrem patruelem suum super bonis patrimonialibus et maternis ac patruelibus rebusque aliis per medium certorum arbitrorum facte et consumate, solutis quindecim florenis Hungaricalibus prime rate, ex vi concordie huiusmodi ipsi domino Iohanni fratri suo, de quibus eum quittavit per presentes, residuos viginti florenos eciam Hungaricales pro bonis prefatis et eorum occasione dicto domini Iohanni solvere et in manus domini Iohannis senioris Dlugosch canonici Cracoviensis vel in absencia sui domini Iohannis iunioris Dlugosch germani ipsius reponere hinc ad festum Circumcisionis Domini proxime affuturum se sub penis excommunicacionis in ipsum casu, quo in solucione negligens fieret et remissus, per dominum officialem Cracoviensem pro tempore existentem virtute laudi ferendis, quibus se subdidit, obligavit et obligat. Qui quidem dominus Iohannes ad tollendum prefatos $\mathrm{XX}^{\mathrm{ti}}$ florenos a domino Andrea predicto creditore necnon ad quittandum de eisdem pro ipsisque, dum necesse fieret processus, extrahendum et subiuvandum, constituit procuratores suos dominos Iohannem seniorem et Iohannem iuniorem Dlugoschowe, canonicos Cracovienses, absentes tamquam presentes, ambos in solidum, ut in forma meliori promittentes de rathihabicione. Presentibus dominis Iohanne de Schebnya notario, Petro Kansii advocato de Kazimira et Iohanne fratre religioso de tercia regula s. Francisci de Luthownicza testibus ad premissa.

[na marg.] 1465 prima mensis Ianuarii dominus Iohannes de Stobnicza presbiter receptus est manualiter levatos viginti florenos in auro a nobili Andrea de Crolewycze residui debiti hic contenti, ipsum de predictis florenis quittavit et liberum misit in perpetuum, promitens eum occasione huiusmodi florenorum ab impedimento quodlibet defendere. Presentibus Stanislao Dach ${ }^{1}$ de Iurczicze et Nicolao Mathva de Vyllemska (?) nobilibis. Offic. Crac. 12 s. 222.

57

19 II 1464

Paulus de Glowini ${ }^{1}$ decanus principalis et magister Nicolaus Spiczmer cantor Cracoviensis pro eo fideiussor unus pro alio cavendo et se principalem ponentes ambo manu coniuncta et in solidum omnibus iuris et facti beneficiis et remediis renunciando venerabilibus dominis Iohanni Dlugosch seniori et Iohanni Dlugosch iuniori canonicis Cracoviensibus centum florenos Hungaricales ex causa certi debiti hinc ad festum s. Michaelis proxime venturum se sub pena excommunicacionis solvere obligarunt et insuper idem dominus decanus dictum suum fideiussorem omnino dicti obligati

561 Stanisław Dach, dziedzic Jurczyc (1476): AGZ XVI nr 1180.

571 Paweł z Głowni (Głowiński) h. Godziemba, prepozyt gnieźnieński, dziekan krakowski (1451), sekretarz królowej Zofii, zm. W r. 1493: Przybyszewski, Wypisy, I, s. 44; PSB VIII, 132-133. 
promisit reddere indempnem sub penis eisdem. Et pro maiori cautela et firmitate dictus dominus Paulus fratrem suum dominum Andream, quam primum Cracovie constituetur ad coobligandum debitum predictum addiciet; qui se modo premisso obligare debebit sub penis predictis. Presentibus dominis Ulrico baccalario in decretis plebano in Gebolthow, Petro Glowa ${ }^{2}$ cive Cracoviensi et aliis multis. Actum die XIX Februarii.

Offic. Crac. 12 s. $253-254$.

Stanislaus Sternbach et Margaretha coniuges de Cracovia cedendo liti et cause ipsis per executores olim maystri Pauli de Zathor canonici Cracoviensis mote et agitate pro certis florenorum summis in actis officialiatus obligatis et per eos prefato olim domino Paulo seu domino Iohanni Dlugosch seniori canonico Cracoviensi ipsius Pauli factori interscriptis, mortificando dictam obligacionem pro omnibus et singulis debitis, eisdem quinquaginta florenos Hugaricales succesive, videlicet duodecim cum medio ad s. Michaelis anni presentis et duodecim cum medio florenos ad $\mathrm{s}$. Stanislao de Mayo et duodecim cum medio florenos ad s. Michaelis anni affuturi et residuos duodecim florenos cum medio ad s. Stanislai de Mayo anni extunc sequentis, videlicet millessimi CCCCLX septimi, festa in manus predictorum dominorum executorum, videlicet Mathie de Blandow ${ }^{\mathbf{1}}$ et Iohanis de Rzeschow canonicorum Cracoviensium manu coniuncta et in solidum se sub penis excommunicacionum solvere obligarunt. In presencia dicti domini Mathie de Blandow hanc obligacionem recipientis et suo ac dicti executoris sui nominibus cavendo de rathihabicione, de aliis ipsos coniuges dimittendo liberos et indempnes reddere promittendo. Presentibus dominis Iohanne de Schebnya ad S. Stanislaum in Rupella Kazimierie plebano et Stanislao de Kazanow notariis publicis.

Offic. Crac. 12 s. $478-479$.

Iacobus [de] Dambno capitaneus Cracoviensis centum florenos cum quindecim in auro nobili Thome de Nawoyowa ${ }^{\mathbf{1}}$ in actis istis superius per dominum Iohannem seniorem Dlugosch canonicum Cracoviensem obligatos manu coniuncta et in solidum cum dicto domino canonico solvere obligat hinc ad festum s. Stanislai in Mayo sub pena excommunicacionis.

Offic. Crac. 12 s. 530.

Nicolaus Spyczmeri decretorum doctor cantor, Iohannes senior Dlugosch et Iohannes iunior Dlugosch canonici ecclesie Cracoviensis pro reverendissimo in Christo patre et domino Iohanne ${ }^{1}$ Dei gracia episcopo Cracoviensi fideiussores omnes manu coniuncta et in solidum, unus pro alio cavendo et se principalem debitorem ponentes centum florenos et septuaginta florenos Hungaricales puri auri et iusti ponderis et viginti marcas peccuniarium pro

2 Piotr Głowa, mieszczanin krakowski (1455-1477): Acta rectoralia, nr 276; Cracovia artificum $\mathrm{nr} 485,674$.

591 Tomasz, dziedzic Nawojowej (1435-1469): Mat PSH-G PAN.

601 Jan Lutkowic (Lutek) z Brzezia h. Doliwa, Biskup krakowski (1464-1471): PSB X, s. $443-445$. 
molendino dicto Zaby mlyn ${ }^{2}$ in Pradnyk in terra Cracoviensi sito per prefatum dominum Iohannem episcopum aput prefatam Annam comparato et empto obligarunt se solvere prefati domini fideiussores successive, videlicet quinquaginta et septem florenos in auro et septem marcas peccuniarum ad s. Iohannis Baptiste, quinquaginta septem florenos in auro et septem marcas peccuniarum ad Nativitatis Domini festa proxime et immediate se sequencia et residuos quinquaginta florenos et sex florenos ac sex marcas peccuniarum ad aliud festum s. Iohannis anni Domini millesimi quingentesimi sexagesimi octavi, sub penis et censuris ecclesiasticis, renunciantes omnibus excepcionibus, appellacionibus, viis, modis et alis quibuscumque modis et remediis solucionem de presenti huiusmodi impedientibus. Presentibus dominis Stanislao de Swyradycze ${ }^{3}$ canonico et officiali Cracoviensi generali, Iohanne Bothurzinšky ${ }^{4}$, Daniele Skawinsky ${ }^{5}$ nobilibus, Nicolao Myechowski de Myehow notario necnon domino Luca de Konopnycza presbyterio. Et casu, quo interim nobili et providi viri domini Waltherus ${ }^{6}$ procurator generalis, Iohannes Thesnar et Nicolaus Crydlyar ${ }^{7}$ cives et consules Cracovienses debitum huiusmodi centum septuaginta florenorum et viginti marcarum per prefatos dominos canonicos obligatum solverint et extenuaverint, pro quo debito idem domini consules similiter cavendo pro domino prefato reverendissimo episcopo aput acta consulum civitatis Cracoviensis se obligaverunt illud soluturos prefate domine Anne Harthlipowa. Extunc memorati domini cantor et canonici Cracovienses erunt-liberi a solucione prefatorum centum septinginta florenorum et viginti marcarum per eos obligatorum et absoluti. Presentibus quibus supra.

[na marg.] 146 VIII mensis Ianuarii Petrus Schalomonouicz ${ }^{8}$ et Anna, mater eius de Cracovia reverendissimum dominum Iohannem episcopum Cracoviensem et suos fideiussores hic contentos de ratha Nativitatis Domini, videlicet quinquaginta et septem florenis et septem marcis hic contentis, quos ab eodem domino episcopo nomine puerorum olim Harthlipowa receperunt numeratos et paratos, quittaverunt et liberos miserunt. Presentibus dominis Petro doctore, Paulo Paulbruch consulibus, Petro Stary et Nicolao Gawronsky ${ }^{9}$ et aliis.

Offic. Crac. 12 s. 734 (skasowany zapis) s. 739-740.

2 Żabi Młyn na Białym Prądniku, obecnie dzielnicy Krakowa, zakupił w r. 1464 Hartlib, rajca krakowski: Mat. PSH-G PAN.

s Stanisław ze Świradzic (Sieradzic) Swiradzki h. Zabawa, kanonik krakowski (1462-1495), prepozyt kielecki, wikariusz in spiritualibus krakowski (1489-1492), oficjał krakowski (1456-1470, 1477-1490), administrator biskupstwa krakowskiego (1471, 1488-1489): Przybyszewski, Wypisy I, s. 19.

4 Jan Boturzyński h. Łzawa, kanonik krakowski (1487), prepozyt sądecki i Sw Jakuba na Kazimierzu w Krakowie, pleban w Wietrzychowicach, Modlnicy, Radomsku i Igołomi, zm. w r. 1524: Przybyszewski, Wypisy, I, s. 86.

5 Daniel Skawiński z Krzywaczki (1467): StPPP II nr 3885.

"Walter Kesinger (Waltek), syn Mikołaja Kesingera z Norymbergi h. Eabędź, właściciel Trzebini i Wieży, wielkorządca krakowski (1460-1470), zm. w r. 1479: Przybyszewski, Wypisy I, s. 18.

7 Mikołaj Kreidler z Wrocławia, mieszczanin i rajca krakowski, przyjęty do prawa miejskiego w Krakowie w r. 1453, rajca krakowski (1459), zm. W r. 1477: J. Ptaśnik, Studia nad patrycjatem krakowskim, „Rocznik Krakowski” 16 (1914), s. $23-25$.

8 Piotr Salomonowicz h. Eabędź, rajca krakowski (1479), zm. w r. 1515: Ptaśnik, jw., s. $33-39$.

9 Mikołaj Gawroński (z Gawron), kapelan kościoła Sw. Anny w Krakowie (1490): Kod. UJ III, s. 143. 
Venerabilis dominus Iohannes Dlugossius custos Wysliciensis canonicus Cracoviensis et Sandomiriensis nomine suo et tocius capituli prelatorum et canonicorum ecclesie collegiate Sandomiriensis recognovit se arrendasse et in arendam conduxisse decimas manipulares cum canapalibus in villis Pothporow, Wolya Podporowska alias Cozakaley, in Dluga, Dluska Wolya, Czarnoczin, Casschow, Caschowska Wolya, Guthow et in Wolya Guthowska ${ }^{1}$ in districtu Racomensi excrescentes hinc ad decem annos immediate sequentes et ulterius, quamdiu arrendator infrascriptus voluerit, videlicet anno presenti pro quinquaginta marcis pecuniarum nobili domino Clementi de Rathosin et Corythkow ${ }^{2}$ presenti. Quas quiquaginta marcas racione arrende ipsarum decimarum anni presentis ipse dominus Clemens debebit solvere et obligavit sub pena excommunicacionis ad festum s. Bartholomei anni proxime affuturi, aliis vero annis, videlicet incipiendo a futuro et sequentibus, quamdiu ipsas decimas tenuerit, de sexaginta marcis pecuniarum, quas aliter singulis annis eisdem pro dicto festo, s. Bartholomei prefatis dominis capitulo ecclesie Sandomiriensis in manus dicti domini Iohannis Dlugosch sub penis excommunicacionis soivere obligavit. Et ipse dominus Iohannes Dlugosch promisit eum reddere idempnem occasione decimarum earundem, videlicet a grandine ad festum s. Jacobi et a bello [?] ad festum s. Michaelis, sub pena eadem, concedens sibi li-bertatem dictas decimas quando voluerit eciam durante dicta arrenda dimittenci. Presentibus ibidem dominis strenuo Zegotha Rythersky milite de Ryther ${ }^{3}$, Michaele cantore et psalmista ecclesie Cracoviensis et Alberto de Sbyluthow familiare dicti Iohannis Dlugosch canonici ac me Stanislao Grodek huius facti scribe promittens hinc inde dictum contractum et arendam tenere et servare sub penis prefatis.

Offic. Crac. 12 s. 481.

Johannes de Pnyow ${ }^{1}$ decretorum dactor archidiaconus et condam administrator ecclesie Cracoviensis principalis et nobiles Egidius de Sudol ${ }^{2}$ et Skarbek de Zastamppow ${ }^{\mathbf{8}}$ pro eo fideiussores eciam ponentes se debitores principales, omnes manu coniuncta et in solidum unus pro alio caventes et se principalem debitorem ponentes, ex concordia inter ipsum dominum archidiaconum et ex adverso reverendum patrem dominum Jacobum Dei gracia episcopum Wladislaviensem pro perceptis fructibus in ecclesia Sandeczensi tempore pro-

611 'Potworów, Wola Potworowska, Długie, Dłuska Wola, Czarnocin, Kaszów, Kaszowska Wola, Gutów, Gutowska Wola - wsie w pow. radomskim, z których dziesięciny należały do stołu arcybiskupa gnieźnieńskiego i zostały zakupione przez Długosza dla mansjonarzy sandomierskich z legatu Tomasza Strzempińskiego (zob. niżej nr 74): Lib. Ben. I, s. 390-393.

- Klemens Ratoski h. Szeliga, właściciel Korytkowa w opoczyńskim (1470-1480): Lib. Ben. I, s. 339.

3 Żegota Ryterski z Rytra h. Topór (1470-1480): Lib. Ben. I, s. 35 nn.

621 Jan z Pniowa (Pniewski) h. Odrowąż, doktór dekretów, notariusz Zbigniewa Oleśnickiego, oficjał generalny, administrator biskupstwa (1460), kanonik gnieźnieński, krakowski (1440), sandomierski, archidiakon krakowski (1451), pleban w Wojniczu, rektor Uniwersytetu Krakowskiego, zm. w r. 1476: Przybyszewski, Wypisy I, s. 10 .

2 Idzi z Sudołka koło Wrocimowic, Awdaniec (1444-1469): Mat. PSH-G PAN.

s Skarbek Piwko ze Stradowa (1443-1474): jw 
visionis dicti domini Jacobi ad eumque spectantibus facta, inita et consumata, sentencialiter dicto domino episcopo ducentos florenos Hungaricales successive, videlicet centum ad festum Nativitatis Christi proxime venturum in manus domini Nicolai prepositi in Tharnow et reliquos centum florenos ad aliud festum eiusdem Nativitatis Christi anni proxime affuturi domini Johannis Dlugosch senioris canonici Cracoviensis se sub penis excommunicacionum per dominum officialem Cracoviensem pro tempore existentem, cuius iurisdiccionis et cohercioni se sponte submiserunt, ferendis, renunciantes omnibus excepcionibus, allegacionibus et quibusvis cautelis iuris et facti solvere obligarunt, pro aliis vero fructibus per ipsum dominum archidiaconum tunc administratorem et suos officiales perceptis et sibi presentatis idem dominus episcopus ipsum dominum archidiaconum liberum misit et absolvit in perpetuum, condicione et excepcione in littera eiusdem domini episcopi sibi domino archidiacono desuper data expressis in sui robore quoad alia debita extrahenda et alias prout in eadem littera asseruerunt contineri, permanente et insuper idem dominus archidiaconus Cracoviensis litteram regie maiestatis, ut asseruit, quittanciam de quingentis florenis vel marcis, prout in eadem expressius continetur, dicto episcopo condidit et presentavit. Presentibus ibidem dominis prefato Johanne Dlugosch seniore, Johanne Regula ${ }^{5}$, Stanislao Skawiniensi, Mathia canonico Kyelcensi et vicario Cracoviensi perpetuo et aliis multis. Actum die Veneris XXVIII May in domo domini decani ${ }^{6}$ Cracoviensis hora vesperarum. Offic. Crac. 12 s. 904-906.

Iohannes Rzessowsky et Iohannes senior Dlugosch canonici Cracovienses, Andreas Pyenyaszek de Cruslowa ${ }^{\mathbf{1}}$ in solidum manu coniuncta et omnes pro alio caventes et se principales debitores ponentes pro magnifico domino Jacobo de Dambno capitaneo et Regni Polonie cancellario principali debitore recognoverunt ipsum dominum capitaneum a generoso domino Iohanne Quasznyowsky de Cwasznyow ${ }^{2}$ trecentos florenos Hungaricales auri puri, boni et iusti ponderis in mutuum recepisse. Quosquidem tricentos florenos ipsi domini Iohannes Rzessowsky et Iohannes senior Dlugosch ac Andreas Cruslowsky ponentes se principales debitores obligaverunt solvere prefato domino Iohanni Qwasznyowsky infra hinc ad festum Purificacionis sancte Marie proximum sub penis et censuris ecclesiasticis, monicione quindecim dierum dumtaxat in facie ecclesie ad kathedralem Cracoviensem per edictum premittenda contra eosdem dominos obligantes, alias extunc lapsis in quindecim diebus sentenciis excommunicacionum se subiecerunt; renunciantes omnibus litteris regalibus, causis, appellacionibus, pignoribus, aliis modis dilacionis regulis et causis dilatacionem solucionis impedientibus per pressum et non evadere ipsum dominum Iohannem Quasznyowski nisi cum paratis florenis alias in forma meliori. Presentibus dominis Petro Barczkowsky in Raczlauicze, Iohanne in Os-

4 Stanisław Świradzki: por. 60 przypis 3.

"Może Jan z Reguł h. Stary Koń, profesor medycyny Uniwersytetu Krakowskiego, zm. w r. 1515: PSB X, s. 472-474.

W domu Pawla z Głowni.

631 Andrzej Pieniążek z Krużlowej, podczaszy krakowski (1467-1486), starosta czorsztyński (1468), muszyński (1468-1469): Fedorowicz, s. 276.

2 Jan Kwaśniowski h. Stary Koń $(1470-1480)$ : Lib. Ben. II, s. 196. 
swyaczim, Michaele Donathkowsky in Slawoschow ${ }^{3}$ plebanis, Nicolao Bydlinski nobili ${ }^{4}$ et Iohanne de Sandecz testibus ad premissis.

[Na marg.:] 1470 die Martis XIII Februari Iohannes Kwaszniowsky principalis hic contentus, recipiendo a dominis hic contentis centum florenos ad racionem debiti hic contenti, ipsos de eisdem centum florenis quittavit et perpetue absolvit, obligacione de residuo in suo robore permanente. Presente Iohanne de Rupella ${ }^{5}$, Nicolao Jawor ${ }^{6}$ de Przeginia nobili ac Nicolao Szczepanowsky burgrabio in Byecz ${ }^{7}$.

Offic. Crac. 12 s. 997.

64

$20 \vee 1469$

Die Veneris XX mensis May Cracovie in curia episcopali hora vesperorum inter venerabiles dominos Johannem seniorem Dlugosch canonicum et Johannem Woyschik ${ }^{1}$ custodem Cracoviensem executores testamenti olim domini Nicolai de Zapolicze ${ }^{2}$ plebanum in Proschowicze actores ex una et honorabilem magistrum Paulum de Schadek $^{3}$ magistrum capelle regie maiestatis modernum ibidem in Proschowicze plebanum reum ex alia partibus, reverendissimus in Christo pater dominus dominus Johannes Dei gratia episcopus Cracoviensis auditis ipsarum parcium differenciis propositisque et responsis summarie finaliter decrevit, quod ipsi domini executores omnia frumenta stancia anni preteriti per dictum dominum Nicolaum testatorem derelicta et deservita percipient. In quorum percepcione ipse magister Paulus easdem non impediet. Executores et similiter columbacionem eiusdem anni proxime preteriti dicti domini executores in toto habebunt nec non quartam partem decimarum et aliorum proventuum anni nunc presentis et pro messe futura pretextu anni gracie de eadem ecclesia in Proschiwicze recipere debebunt pro voluntate dicti testatoris convertendum; offertorium vero, quod a tempore mortis eiusdem Nicolai de Zapolicze provenit, sibi magistro Paulo plebano moderno debebitur ex integro. Et premissa ipse partes observabunt hincinde sub censuris ecclesiasticis. Presentibus ibidem dominis Stanislao de Swiradzicze officiali generali magistro Johanne Baruchowsky ${ }^{4}$ canonicis Cracoviensibus, magistro de Latoschin ${ }^{5}$ decretorum doctore, Stanislao de Cobilino ${ }^{6}$ similiter decretorum

3 Słaboszów, wieś w pow. ksiąskim.

4 Mikołaj Bydliński h. Mądrostki (1467-1468): A. Boniecki, Herbarz polski, t. 2, Warszawa 1900, s. 274

5 Jan Skałka z Szebni.

6 Mikołaj Jawor z Przegini (1479): StPPP II, nr 4214.

7 Mikołaj Szczepanowski, burgrabia w Bieczu (1467-1485): Fedorowicz, s. 284. 641 Jan Wojszyk z Wojczy w pow. stopnickim h. Powała, kustosz krakowski (1454), kanonik Św. Jerzego na Wawelu, altarysta Św. Marii Magdaleny w kaplicy mansjonarzy przy katedrze krakowskiej, zm. w r. 1482: Przybyszewski, Wypisy I, s. 10 .

2 Mikołaj Zapolicki (Zapolski) h. Pobóg, kanonik krakowski (1456-1469): Przybyszewski, Wypisy I, s. 11.

3 Pawel z Szadka, magister artium niwersytetu Krakowskiego (1457): LP, s. 34,48 .

4 Jan z Baruchowa (Baruchowski) h. Doliwa, doktor dekretów, kanonik (1469), kaznodzieja katedralny krakowski, kanonik i kantor gnieźnieński, pleban w Koniemłotach, rektor Uniwersytetu Krakowskiego, wikariusz generalny in spiritualibus (1501-1503), zm. w r. 1507: Przybyszewski, Wypisy I, s. 45.

5 Jan z Latoszyna (Latoszyński) h. Gryf, doktor teologii i dekretów, rektor Uniwersytetu Krakowskiego, kanonik krakowski (1472), kanclerz Fryderyka Jagiellończyka (1488-1490): Przybyszewski: Wypisy I, s. 40.

6 Stanisław z Kobylina, doktor dekretów, kanonik skalbmierski, pleban w Lu- 
doctore plebano in Luborzicza, Johanne de Jaroczino, Johanne de Gorzicze et Martino Lubomyslsky notariis curie testibus ad premissa.

Episcop. Crac. 1 K. 26 r.

65

9 IV 1470

Iohannes Cloba principalis Nicolaus Rotifex ${ }^{1}$ et Nicolaus Sydzina pro eo fideiussores consules et opidani de Vyelyczka omnes manu coniuncta et in solidum unus pro alio cavendo se principalem debitorem ponendo pro omnibus debitis in quibus alias ipse Iohannes Clyoba olim domino Nicolao Proschowsky $^{2}$ fuisset et esset obligatus, cedendo liti et cause, quinquaginta florenos Hungaricales dominis Johanni Voyschyk custodi et Iohanni Dlugosch seniori canonico Cracoviensi executoribus testamenti dicti olim Nicolai Proschowsky successive, videlicet viginti quinque ad s. Michaelis et residuos viginti quinque ad Pasce festa ẻxtunc proxime affutura et se immediate sequencia, sub penis et censuris ecclesiasticis, renunciantes quibusvis allegacionibus, solucionem impedientibus, solvere obligarunt et insuper dictus dominus Iohannes prefatos fideiussores occasione dicte caucionis promisit reddere indempnes et casu quo morietur extunc consignat eis solucionem dicti debiti in bonis eius mobilibus et immobilibus recipiendam et faciendam cum effectu, volens et instituens ipsos fideiussores esse primos creditores ad bona eadem modo premissa; pro quo quidem debito obligato et cuius occasione ipsi executores prefatum dominum Iohannem ac fideiussores ac quilibet in bona successores debebunt $a b$ omnibus impedimentibus teneri, defendere et evincere propriis sumptibus et expensis et pro ulteriori sive aliis quibusvis eum non impetere neque inquietare. Presente Stanislao de Rzeszow clerico nostre curie notario dicti domini Iohannis Dlugosch prefatam obligacionem et confitente. Presentibus domino Iohanne de Schebnya plebano s. Stanislai in Rupella, Iohanne preposito s. Hedvigis ${ }^{\mathbf{3}}$ in Ponte Regali, Iacobo in Chodow plebano, Stanislao de Oppathowyecz notario.

[Na marg.:] Die Iovis XI Octobris Iohannes Cloba retroscripsit: XXV florenos ad Pasce et XII cum medio ad s. Michaelis anni sequentis domino Dlugossio sub pena excommunicacionis solvere obligavit. Presentibus dominis notariis.

Offic. Crac. 12 s. $1128-1129$.

66

12 VI 1471

Jacobus opidanus de Wislicia constituit procuratorem venerabilem dominum Johannem seniorem Dlugosch canonicum Cracoviensem ad concordandum cum honorabili domino quondam notario domini administratoris et ad compromittendum in arbitros et superarbitrum ac ad suscipiendum penam et ad emologandum sentenciam ut in forma meliori. Presentibus ut supra.

Episcop. Crac. 3 k. 51 v.

borzycy, rektor Uniwersytetu Krakowskiego, zm. w r. 1490: Przybyszewski, Wypisy I, s. 26 .

651 Mikolaj Rotifex, lawnik wielicki (1443-1468): Kod. wiel., s. 27, 37, 70.

2 Mikołaj Zapolicki.

3 Jan Bartoszewski h. Zadora, prepozyt bożogrobców na Stradomiu (1473):

S. Nakielski, Miechovia, Kraków 1634, s. 533.

4 Chodów, pow. ksiąski. 
Iurispatronatus et presentandi prebende sanctorum Philippi et Jacobi in Cleparz ${ }^{1}$ in causa inter dominos Johannem de Schebnya dominorum Jacobi de Conyeczpolye ${ }^{2}$ et eius litis consortum et ex adverso Lazari de Mnynoga ${ }^{3}$ domini Marci de ibidem presentatos eorumque presentantes vertenda, reverendissimus in Christo pater dominus Johannes Dei gracia episcopus obtulit se ipsis partibus visis videndis facere iusticiam competentem, receptis assessoribus per ipsas partes mutuo et hincinde eligendis; quosquidem assessores hincinde, videlicet dictus Johannes de Schebnya Jacobum de Schadek canonicum Cracoviensem et Clementem de Gorka ${ }^{4}$ rectorem Universitatis decretorum doctores et magister de. Welyczka ${ }^{5}$ nomine eorundem Marci et Lazari Sandivogium de Thancin ${ }^{6}$ licenciatum in decretis prepositum Skarbimiriensem et Johannem Dlugosch seniorem canonicum Cracoviensem, nominaverunt et eorum quilibet nominavit pro parte sua ita, quod altero eorundem assessorum a loco Cracoviensi absente, se legitima causa excusante, licebit eis et eorum cuilibet unum alium idoneum et non suspectum nominare et eligere, ipsos hincinde assessores vel assessorias eorundem hinc ad feriam secundam proximam post dominicam Reminiscere comportando et expediendo, alias in defectu, prout de iure dominus decernat, determinandum. Presentibus notariis, sociis circa premissa.

Episcop. Crac. 3 k. $65 r-65 v$.

68

9 XI 1474

Mathias Bassaak de Cracovia $^{1}$ sponte ac libere sentenciam arbitralem inter ipsum ex una et Johannem sartorem alias Byaly Jan ${ }^{2}$ ac Dorotheam coniuges de Cracovia ex alia partibus per medium reverendissimi domini episcopi ac Johannis Dlugosch senioris canonici Cracoviensis et nonnullos alios arbitros hincinde assumptos et locatos super omnibus differenciis factam et litibus inter ipsas partes hactenus tam in Curia Romana quam hic in partibus ventilatis factam emologando ac penam centum florenorum in ipsa concordia seu sentencia arbitrali vallatam et interpositam assumendo et aprobando, se mutuo liberos ad eisdem litibus dimiserunt et presertim ipse Mathias Bassaak prefatos Johannem Byaly et Dorotheam coniuges de singulis accionibus et litibus necnon monitoriis et quibusvis aliis processibus excommunicacionum et ápellacionibus qualitercumque habitis et promulgatis liberos et absolutos di-

671 Kościół Sw. Filipa i Jakuba znajdował się przy dzisiejszej ul. św. Filipa, zburzony został w r. 1801: J. Dzikówna, Kleparz do r. 1528, Kraków 1932, s. 90-92. Biblioteka Krakowska. T. 74.

2 Jakub Koniecpolski, syn Przedborza (1462): PSB XIII, s. 517.

3 Łazarz z Minogi, syn Marka, student Uniwersytetu Krakowskiego (1470): AS, S. 202 .

4. Klemens z Górkî, student Uniwersytetu Krakowskiego (1444), profesor dekretów i rektor, zm. ok. r. 1483: PSB XII, s. 589.

5 Jan Wieliczka, długoletni adwokat konsystorza krakowskiego (od r. 1462), żonaty z szlachcianką Anną Głębowską, zm. w r. 1504: Przybyszewski, Wypisy II, s. 17 .

6 Sędziwój z Tęczyna h. Topór, doktor dekretów, kanonik krakowski (1457-1479), kantor wiślicki, prepozyt skalbmierski, pleban w Niedźwiedziu, oficjał generalny krakowski $(1470-1471)$, zm. po r. 1473: Przybyszewski, Wypisy I, s. 14.

681 Maciej Bassak z Krakowa, prokurator konsystorza krakowskiego (1465-1488): Cracovia artificum, nr 997.

2 Jan Biały, starszy cechu krawców (1480): Cracovia artificum, nr 752. 
- misit, submittens se sub pena huiusmodi vallata centum florenorum eosdem coniuges' amplius quoquomodo non inquietare aut molestare quorundam schube, cinguli argentei, pallii, coclearium argenteorum et cantharorum staneorum occasione. Super quibus huiusmodi concordiam amicabilem confessus est fuisse subsecutam et insuper prefatus Johannes Byaly suo et dicte consortis sue nominibus parens similiter dicte concordie et rei iudicate in eadem et composite reposuit hic apud actu tres florenos Hungaricales in ipsa concordia dicto Mathie Bassak adiudicatos, quos tres florenos ipse Mathias Bassak personaliter comparens ab eodem Johanne Byaly sartore recepit et manualiter levavit, de quibus tribus florenis et omnibus rebus prefatis dictos coniuges idem Mathias Bassaak quittavit et quittat per presentes. Presentibus ibidem dominis Johanne Lechoczky, Johanne de Land $^{3}$ et Urbano do Gora notariis testibus ad premissa. Episcop. Crac. 3 k. 97 r.

Venrabilis dominus Stanislaus de Swiradzycze prepositus Kyelciensis et canonicus Cracoviensis cavendo pro nobili domino Pyelsch ${ }^{1}$ de eadem Swiradzicze germano suo seque principalem debitorem ponendo necnon venerabiles domini Johannes Dlugosch senior de Nyedzyelsko custos Wislicziensis, Mathias de Blandow et Johannes de Latoschin officialis generalis, decretorum doctores, canonici Cracovienses similiter caventes pro ipso domino Stanislao Swiradzsky et se principales ponentes, obligarunt se manu coniuncta et in solidum ex concordia et unione inter ipsum dominum Stanislaum nomine eiusdem domini Pyelsch germani sui ac universitatem dominorum doctorum et magistrorum collagiatorum domus artistarum Studii Cracoviensis per medium reverendissimi in Christo patris domini Johannis Dei gratia episcopi Cracoviensis initis et factis eisdem dominis doctoribus et magistris domus artistarum centum marcas comunis pecunie hinc ad festum Nativitatis Christi proxime affturum occasione debitorum quorumlibet, tum intuitu cautionum fideiussorialium tum eciam vadiorum et damnorum pro olim Martino Byrowo de Przybinycze ${ }^{2}$ contractorum, alias in eodem domino Pyelsch et pro suo iure terrestri et in vim certàrum concordiarum subsecutarum, perlucratorum et aquisitorum dare, solvere sub censuris ecclesiasticis in eos ferendis, quibus se sponte, renunciando omnibus cautelis iuris et facti, submiserunt et submittunt. Quos quidem dominos fideiussores supradictos prefatus dominus Stanislaus Swiradzsky racione dicte caucionis sub penis eisdem relevare et reddere indempnes promisit in forma meliori. Quiquidem domini, videlicet Stanislaus Swiradzsky de Swiradzicze suo et eiusdem domini Pyelsch germani sui ac magister Mathias de Schydlow ${ }^{8}$ prepositus dicte domus artistarum Studii Cra-

3 Jan, syn Stanisława z Lądu, notariusz konsystorza krakowskiego (1465-1472), pleban w Drogini (1476-1477), pleban w Gnojnie (1481-1492): Regesta (BS) nr 249; Kod. UJ III, s. 13, 50, 90, 117, 139, 195; Cracovia artificum nr 648.

691 Pielsz Świradzki h. Zabawa, brat Stanisława oficjała krakowskiego, dziedzic Przybenic, pow. proszowicki $(1470-1480)$ : Lib. Ben. I, s. 527.

2 Marcin Byrowo, dziedzic Przybenic, procesujący się z Uniwersytetem Krakowskim o bieg rzeki (1432-1462): Kod. UJ I, s. $167-168$, II, s. $65-66,182,195-196$, $266-269$.

3 Maciej z Szydłowa, magister artium Uniwersytetu Krakowskiego (1468), doktor dekretów i teologii, dziekan kolegiaty św. Floriana na Kleparzu, pleban w Imbramowicach, Olkuszu, Szydłowie, Łętkowicach, kanonik krakowski (1498) i kaznodzieja katedralny krakowski, zm. w r. 1519: PSB XIX, s. 37-38. 
coviensis, similiter suo et omnium dominorum doctorum et magistrorum collegiatorum domus eiusdem nominibus hincinde cavendo sufficienter de ratihabicione ipsorum se vicissim de aliis omnibus pecuniarum summis perlucratis litibusque, causis et accionibus tam in Gnezna quam hic in foro seculari et alias videlicet motis et agitatis indecisis pendentibus, dimiserunt et absolverunt. Ipsas lites, causas, acciones et differencias inter eos quomodolibet exortas tam regales quam prophanas, inter se extinxerunt et mortificarunt, easdem nunquam mutuo repetituri, salvo eo, quod prefati domini doctores et magistri, collegiati domus eiusdem dumtaxat dictis centum marcis, ut premissum est, eis obligatis pretextu concordie moderne debent esse paccati et contenti ac eciam salvis condicionibus de meatu aque in prioribus concordiis contentis, qui eciam domini doctores et magistri restituere debent litteras et iura super huiusmodi lucris prefato domino Stanislao Swiradzsky sub pena hincinde mille florenorum vallata, quam ipse partes inter se ibidem vallarunt, parti tenenti per medium et ipsi reverendissimo episcopo per medium per partem contravenientem ipso facto solvenda. Quam quidem obligacionem et pene valacionem partes eisdem nominibus, quibus supra, ibidem susceperunt et approbarunt in forma. Presentibus ibidem venerabilibus dominis Arnolpho de Myrzinyecz ${ }^{4}$ doctore, Petro Vapowski ${ }^{5}$, canonicis Cracoviensibus et Paulo Chorazycz ${ }^{6}$, preposito Premisliensi.

Episcop. Crac. 3 \%. 110 r $-110 v$.

Decimarum in Trawnyk ${ }^{1}$, Wola Oleschnyczska ${ }^{2}$ et Hydzikowycze $^{1}$ in causa super iure percipiendi easdem reverendissimus dominus episcopus ${ }^{3}$ et $\mathrm{Ni}-$ colaus plebanus in Czemyernyky ${ }^{4}$, easdem ad se hincinde pertinere allegantes, compromiserunt in forma meliori super decreto et decisione pro eisdem ac earum quilibet in dominos Johannem Dlugosch seniorem, canonicum Cracoviensem et Johannem Kazimirsky ${ }^{5}$, officialem Lublinensem in solidurn, quorum decisioni, subiecta re oculis, et aprobacionibus receptis stare voluerunt. Presentibus quibus supra.

Episcop. Crac. 3 k. 112 r.

Nos Johannes Dlugosch et Stanislaus de Swiradzicze prepositus Kyelcensis et canonicus Cracoviensis iudicesque arbitri et arbitratores sive amicabiles compositores per partes infrascriptas vigore compromissi in nos libere facti deputati pronunciamus decernimus et declaramus testamentum olim magistri

4 Arnolf z Mirzyńca koło Mościsk, doktor dekretów i teologii, kanonik gnieźnieński, krakowski (1475), zm. przed 4 I 1491: Przybyszewski, Wypisy I, s. 45.

5 Piotr Wapowski z Radochoniec h. Nieczuja, doktor dekretów, kanonik gnieźnieński, krakowski (1472), dziekan krakowski, sołtys wielicki, zm. w r. 1536: Przybyszewski, Wypisy I, s. 45.

6 Paweł Chorążyc z Wrocimowic i Brzany h. Półkózic, kanonik krakowski (1480-1504), prepozyt.przemyski, pleban w Niegowici, Jaśle, Starym Brzesku: Przybyszewski, Wypisy I, s. 29.

701 Trawniki, Idzikowice, wsie w pow. lubelskim.

2 Zapewne część Oleśnik, pow. lubelski.

3 Jan Rzeszowski.

4 Czemierniki, pow. Iubelski.

5 Jan Kazimierski, prepozyt chełmski, oficjał lubelski (1479-1480): Kod. UJ III, s. $73,74,76$. 
Johannis Proger ${ }^{1}$ sub modificacione infrascripté suum debere sortiri effectum et per duos executores in forma infrascripta quantum ad residuam execucionem exequendam. In primis videlicet, ut altare ad s. Annam ${ }^{2}$ per eos fundatum in sua remaneat firmitate. Item quod de residuis decem marcis censuum per prefatos dominos executores in Proschowicze emptorum quinque marce pro conventu hospitalis Sancti Spiritus in Cracovia in manus domini prepositi et conventus dande cedant. Relique vero quinque marce pro consanquineis proximioribus ad id ius et iusticiam habentibus consignentur, quas in futuris quatuor temporibus proximis tollere incipient illasque percipient usque ad dictorum censuum reempcionem. In casu autem, quo dictus census reemeretur et octingenti floreni restituerentur, patroni altaris predicti quingentos florenos, prepositus cum conventu centum quinquaginta et tandem ipsi consanguinei, videlicet Ursula Fryschphatrowa ${ }^{3}$ et alii, centum L-ta florenos tollent et tenebunt et quilibet suam quottam recipiet et percipiet. Item pronunciamus, quod ipsi domini executores omnes res tam in peccuniis, argento, libris, suppellectilibus et quibuscumque rebus, que in hactenus habent et que non distribuerunt et in execucionem non posuerunt, apud nos vel alterum nostrum reponant, ipsis amicis consanquineis, que nobis videbuntur, consignanda, et alias, ut melius et salubrius videbitur, cum ipsis dominis executoribus disponenda da VIII [diem]. Item quod prefati domini prepositus et conventus ac ipsa Fryschphatrowa et alii amici et consanguinei de dictis ducentis marcis et quibuscumque aliis rebus recipiendis tenebuntur et se obligabunt in utroque iure spirituali et seculari a qualibet persona in casu impedimenti et impeticionis dictos dominos executores evincere et intercedere sub eadem pena excommunicacionis per iudices ordinarios in eos ferenda et promulganda, quibus censuris se sponte submiserunt. Item decernimus, ut prefatam nostram sentenciam sub pena in compromisso contenta mox et sine retardacione teneantur et debent emologare et acceptare. Item prefate sentencie interpretacionem, correccionem et mutacionem nobis ad unum reservamus mensem.

Episcop. Crac. 3 k. 147 r.

Eodem die et loco, quibus supra, venerabiles magistri Johannes de Osswyanczim ${ }^{1}$ sacre theologie professor canonicus ad s. Florianum in Cleparzs et Florianus ${ }^{2}$ plebanus ad s. Stephanum in Cracovia executores testamenti olim magistri Johannis Proger ex una, Ursula Fryschphatrowa germana dicti magistri Johannis Proger, Petrus Pictor ${ }^{8}$ gener et Ursula uxor ipsius Petri Pictoris filia dicte Ursule Fryschphatrowa ex alia partibus omnes vero unani-

711 Jan Proger z Krakowa, bakałarz artium Uniwersytetu Krakowskiego (1430), magister (1433), prepozyt św. Anny w Krakowie, (1442-1469), zm. przed 7 XII 1471: LP, s. 23, 25.

2 O fundacji ołtarza w kościele św. Anny w Krakowie zob. I. Michalewicz, M. Michalewiczowa, Liber beneficiorum et benefactorum Universitatis Jagellonicae. T. 1, Kraków 1978 , s. $24-25$.

3 Urszula Frischnatowa, mieszczanka krakowska (1477): Cracovia artificum, nr 697 .

721 Jan Beber z Oświęcimia, profesor teologii Uniwersytetu Krakowskiego zm. w r. 1482: Słownik pracowników książki polskiej, Warszawa 1972, s. 49.

2 Florian, magister artium, pleban kościoła św. Szczepana w Krakowie (1469-1483): Kod. UJ II, s. 264; III, s. 4-12, 103, 118, 119.

3 Może malarz krakowski Piotr Kos, występujący w 1. 1464-1497: Przybyszewski, Wypisy I, s. 77. 
miter et concorditer recognoverunt personaliter coram reverendissimo domino episcopo et hic apud acta prefatam concordiam occasione testamenti et rerum derelictarum aicti magistri Johannis Proger, prout supra continetur, huc inserti inter se tanquarn propinquos propinquiores per medium supra dictorum dominorum Johannis Dlugosch et Stanislai Swiradzsky canonicorum Craccviensium arbitrorum per eosdem hincinde assumptorum fecisse, aprobasse et emologasse petentes utrobique ipsam concordiam prescriptam immediate per reverendissimum dominum episcopum in omnibus suis clausulis, capitulis et condicionibus admitti, ratificari, confirmari et ratificari. Et dominus reverendissimus visa concordia hincinde eandem, sicut petitum est, admisit, confirmavit et ratificavit et robur perpetue firmitatis decrevit obtinere. Et insuper ibiajem incontinenti predicti domini executores testamenti memorati potestate ipsius execucionis decem marcas census annui tricentos florenos, ut in ipsa concordia continetur, concernen is religiosis fratribus preposito conventui et monasterio sancti Spiritus Hospitalis in Cracovia et dictis Ursule Fryshphatrowa, genero et filie eiusder tamquam propinquis proximioribus ipsius magistri Johannis Proger vita fincti per mecietatem percipiendos, videlicet pro monasterio $S$. Spiritus quinque marcas et eisdem propinquis residuas quinque marcas singulis annis, iuxta litteras empcionis census huiusmodi resignaverunt et pro ipsis monasterio et propinquis consignaverunt per eosdem prepositum et propinquos usque ad reempcioneth efectivam habendum, tollendum, vendendum, donandum, utifruandum et prout ipsis melius et utilius videbitur ad usus eorum beneplacitos convertendum, nihil iuris aut proprietatis dicti executores testamenti pro se deinceps in dictis decem marcis census reservando, sed omnimodo et in totum huiusmodi ius et proprietatem census eiusdem decem marcarum a se abdicando et in ipsos prepositum et propinquos transfundendo, petentes similiter dicti executores eandem resignacionem et transfusionem decem marcarum earundem census per dominum reverendum episcopum recipi, admitti et confirmari. Et dominus reverendissimus episcopus, matura premissa delibaracione admisit et confirmavit et inibi mox prefati Ursula Fryschphatrowa, Petrus Pictor gener et Ưrsula filia eiusdem, propinqui proximiores dicti magistri Johannis Proger, de premissis omnibus contenti existentes confessi sunt per expressum pro parte ipsorum in possessione percepcionis census predicti quinque marcarum se esse et existere singulasque res in concordia eadem prescripta specificata $a b$ eisdem dominis executoribus levasse et exegisse in effectum nec in aliquo occasione dictorum derelictorum seu testamenti ipsos executores denique facere obnoxios, de quibus omnibus ipsi propinqui eosdem executores quittarunt, absolverunt et liberos dimiserunt et amplius non inquietare quoquo modo et eciam ab omnibus impedimentis intercedere et evincere se submiserunt ecclesiasticis sub censuris. Presentibus ibidem dominis Nicolao de Lathouicz ${ }^{4}$ doctore, Johanne Schebnya cancellario et notariis curie testibus ad premissa.

Episcop. Crac. 3 k. $147 r-v$.

73

15 III 1479

Magnificus dominus Jacobus de Dambno castellanus et capitaneus Cracoviensis proposuit contra venerabiles dominos prelatos et canonicos capituli ecclesie Crācoviensis, quomodo ipśi, dum quidam Moyses clericus propter sedi-

${ }^{4}$ Mikołaj z Latowic, magister artium Uniwersytetu Krakowskiego (1468), kanonik płocki: LP, s. 65 . 
cionem et certos suos excessus per familiares suos fuerat captus et succesive in manus dominorum consulum Cracoviensium traditus, verentes periculum mortis sibi imminere, miserant ad magnificenciam suam venerabiles dominos Paulum de Glowina decanum, Johannem Voyschik custodem, Johannem Dlugosch seniorem et Johannem de Slupcza canonicos et gremii ipsorum prelatos et fratres, rogantes nomine suo et dicti capituli magnificenciam suam, quatenus prefatum Moysem clericum de captivitate eadem mittere et relaxare mandaret; promitentes extunc ibidem dicti domini decanus custos et canonici antedicti suo et ipsius capituli nominibus sibi domino castellano et capitaneo pro omni indempnitate et impedimento dictorum familiarium sue magnificencie ac consulatus civitatis Cracoviensis predicte occasione iniuriarum captivitatis et detencionis ipsius Moysi clerici, quod absit, in posterum ab eodem Moyse vel aliis quibuscumque occasione premissa eveniendis tueri, defendere et reddere indempnes, bona fide sub penis dampni et interesse, asseverantes tunc iidem domini decanus, custos et canonici supradicti, quod eisdem ac dicto capitulo honorabilis magister Florianus plebanus sancti Stephani in Cracovia patruus ipsius Moysi similem et equalem pro eorum indempnitate fecisse caucionem et obligacionem, quodque ipse dominus castellanus ad peticionem et promisionem huiusmodi dictorum dominorum decani, custodis et canonicorum et ymmo verius capituli antedicti ipsum Moysen de dicta captivivitate dixerat re.axandum, prout et relaxatus est. Qui tamen Moyses in hactenus pro captivitate et detencione suis predictis prefatos dominos consules Cracovienses ac eciam nonnullos familiares suos ad curiam Genznensem per comissionem sedis apostolice dicitur citasse, eosdem illic trahendo, vexando et dampnificando; petens dictos dominos capitulares ad evincendum et indempnes reddendum a vexacione prefata dicti Moysen eorundem dominorum consulum et familiarium compelli cum litis expensa iusticia mediante. In presencia predictorum dominorum Pauli decani et Johannis custodis, qui ibidem dominus Paulus decanus de consensu dicti domini Johannis Voyschik custodis tunc ibidem presentis et loqui sibi mandantis suo et dictorum dominorum Johannis Dlugosch et Johannis de Slupcza absencium et ymmo tocius capituli nominibus ad dictam proposicionem respondendo animo et intencione legittime litem contestandi confessus est, quod ipse unacum dictis dominis custode et Johanne Dlugosch et Johanne de Slupcza fuit nuncius in hac re a dicto capitulo ad prefatum dominum castellanum, proponendo ei nomine ipsius capituli hanc ipsam promissionem in presencia ex adverso dominorum Johannis Raphael de Tharnow ${ }^{1}$, Jacobi de Radoschownycza ${ }^{2}$, Derslai de Carnycze ${ }^{3}$, Stanislay Swiraczky, Stanislai Visliczky ${ }^{4}$, Johannis Latoschinsky, Mathie Blandowski, Johannis Pyenyazek ${ }^{5}$ canonicorum, qui super responsione eadem taciter facta deliberare voluerunt et dominus reverendissimus ex confessatis huiusmodi dictis domino

73 1 Jan Rafał z Tarnowa h. Leliwa, kanonik krakowski (1445-1481), łęczycki przemyski (1476-1478), zm. po r. 1481: Przybyszewski, Wypisy I, s. 14.

2 Jakub z Radoszownicy (Lelowski) h. Pobóg, kanonik krakowski (1457-1488), wikariusz in spiritualibus krakowski (1463), pleban w Lelowie: Przybyszewski, Wypisy I, s. 14.

3 Dziersław z Karnic h. Lis, doktor dekretów, kanonik krakowski (1466), scholastyk płocki, zm. ok. r. 1495; Przybyszewski, Wypisy I, s. 57.

4 Stanisław, Wiślicki z Korytnicy h. Jelita, notariusz królewski (1466), kanonik krakowski (1471), pleban w Pacanowie, zm. w r. 1482: Przybyszewski, Wypisy I, S. 47.

5 Jan Pieniążek z Krużlowej h. Odrowąż, kanonik krakowski (1474-1482): Przybyszewski, Wypisy I, s. 45. 
decano et custodi decrevit eosdem dominos consules et familiares taliter citatos evincendum, liberandum et indempnes reddendum a dicto Moysen clerico citante et vexante eiusque impedimentis et vexacionibus supradictis accionem eisdem contra capitulum, magistrum Florianum et aliis sua interesse putantes resignando. Presentibus ibidem venerabilibus et honorabilibus dominis Johanne de Schebnya canonico, Johanne Land in Gnoyno et Johanne Gorziczsky in Droginia plebanis notariis curie episcopalis testibus circa premissa.

Episcop. Crac. 3 k. 151 r -151 v.

Capituli ecclesie cathedralis Cracoviensis contra reverendum patrem dominum Johannem seniorem Dlugosch electum ecclesie metropolitane Leopoliensis in causa magister Johannes de Pokrziwnycza nomine eiusdem capituli proposuit, quod quamvis ipsum capitulum Cracoviense in nullo capitulo ecclesie collegiate Sancte Marie Sandomiriensis ocasione cuiusdam aserte summe mille quingentorum florenorum sit obnoxium, nichilominus tamen pretextu sume eiusdem, sicut creditur, per ipsum reverendum patrem dominum Johannem Dlugosch tunc concanonicum et procuratorem dicti capituli ecclesie Sandomiriensis unacum nonnullis decimis de mensa archiepiscopali Gneznensis a decem septem annis citra vel ultra recepte et pro suo beneplacito disposite et converse prefatum capitulum Cracoviense per ipsum Sandomiriensis ecclesie capitulum impetitur, licet iniuste, et vexatur in detrimentum et dampnum ecclesie ipsius Cracoviensis, petens ipsum dominum Johannem Dlugosch ex causa huiusmodi recepcionis et disposicionis summe et decimarum predictarum ad evincendum ipsum Cracoviense capitulum compelli ubicumque, quociens opus fuerit, coram quibuscumque iudicibus quocumque auctoritate fungentibus ac eciam ad perceptas decimas pro summa huiusmodi comparatas seu perceptas peccunias cogi ad reponendum ad sacras edes aut alias in manibus reverendissimi domini episcopi Cracoviensis ${ }^{1}$, necnon inhibicionem unacum aresto in forma debita et fieri consveta ad bona ipsius domini Dlugosch, quibuscumque nominibus censeantur, decerni. In presencia ipsius domini Johannis Dlugosch ad mandatum eiusdem reverendissimi episcopi ibidem pro termino hodierno legittime per se comparentis, qui tandem ad premissa in scriptis realiter obtulit et produxit responsionem huiusmodi, que sequitur sub tenore: Reverendissime in Christo pater et domine graciosissime! Ad proposicionem venerabilium patrum dominorum prelatorum et canonicorum capituli Cracoviensis coram vestra paternitate hodie factam respondet Johannes Dlugosch, quod ipse existens tunc canonicus Sandomiriensis suo et nomine aliorum prelatorum et canonicorum Sandomiriensium, qui tunc erant et ad id consenciebant, et eciam sub ratihabicione et consensu vestre reverendissime paternitatis, qui tinc fuistis ecclesie Sandomiriensis scolasticus et canonicus, consensit mille quingentos florenos Hungaricales per reverendissimum patrem dominum Thomam ${ }^{2}$ episcopum Cracoviensem in profectum ecclesie Sandomiriensis et in fundacionem mansionariorum legatos reverendo patri domino Johanni Gruschczinsky ${ }^{8}$

741 Jan Rzeszowski.

2 Tomasz Strzempiński h. Prus, doktor dekretów i teologii Uniwersytetu Krakowskiego, scholastyk gnieźnieński i krakowski, biskup krakowski (1455-1460): Przybyszewski, Wypisy I, s. 4.

3 Jan Gruszczyński h. Poraj, kanonik gnieźnieński i poznański, kustosz krakowski (1444), biskup kujawski (1451) i krakowski (1463-1464), zm. w r. 1473 jako arcybiskup gnieźnieński: Przybyszewski, Wypisy I, s. 31. 
tunc episcopo Cracoviensi mutuare venerabili capitulo Cracoviensi sub penis camere ad solucionem prefate sume se obliganti fideiubendo et cavendo. Processu vero temporis, dum idem Johannes Gruschczinsky in archiepiscopum Gneznensem de ecclesia Cracoviensi fuisset translatus, ecclesie Sandomiriensi et mansionariis pro dicta summa satisfacturus decimas manipulares mense sue archiepiscopalis in villis Potworow, Potworowska Wola, Dlugye, Dlusska Wola, Kaschow, Kaschowska Wola, Guthow, Guthowska Wola et Czarnoczin ecclesie Sandomiriensis, sub ratihabicione et consensu capituli Gneznensis, donavit perpètuo et inscripsit et literis suo et capituli sigillis roboratis firmavit in capitulo generali pro festo s. Adalberti celebrato, in quo ipse dominus Johannes Gruschczinsky erat presens; scribens et asserens se in eodem privilegio donacionis, ad quod se dominus Johannes Dlugosch refert, prefatos mille quingentos florenos in necessitates ecclesie Gneznensis convertisse datis fideiussoribus notabilibus, qui fideiusserunt et inscripcionem ad acta capituli Gneznensis fecerunt, quod ipse dominus Johannes Gruschczinsky archiepiscopus bona alia prefatis decimis equivalencia debebat infra decennium ecclesie Gneznensi ordinare; per hunc itaque modum ecclesie Sandomiriensi per donacionem dictorum decimarum, Gneznensi vero ecclesie per fideiussoriam caucionem satisfaciens et ecclesie Sandomiriensi possessionem decimarum plenam et pacificam assignans, in qua fuit per plures annos usque ad et post mortem suam, donec modernus reverendissimus dominus Jacobus Gneznensis archiepiscopus ab annis citra quatuor eas per potenciam recepit et que sunt iterum per suam paternitatem ecclesie Sandomiriensis per operam et fatigam eiusdem Johannis Dlugosch restitute, premissis quingentis florenis ipsi domino archiepiscopo solvendis et dato consensu dominus ipse archiepiscopus mille quingentos florenos à fideiussoribus domini Gruschczinsky iuxta eorum inscripcionem et obligacionem exigat. Ex quibus omnibus taliter in veritate gestis, quam eciam veritatem domini capitulares Cracovienses attestantur, vos pater reverendissime domine episcope Cracoviensis, potestis videre et palpare, si in aliquo ego sum capitulo Cracoviensi aut Sandomiriensi obnoxius, culpabilis aut reus, qui omnia fideliter et legittime egi pro utraque ecclesia Cracoviensi et Sandomiriensi utriusque profectum mea opera, diligencia, meis studiis, laboribus, fatigis, impensis, meis eciam periculis rem presentem dirigendo et fideliter, novit Deus, promovendo, nec venio culpandus accusandus aut vexandus pro tantis laboribus et periculis meis nec tenor utramque ecclesiam pro aliquo dampno aut periculo evincere, qui omnia in profectum utriusque ecclesie ordinabam optimo animo et intencione, nulla habens in me nedum maculam aut culpam, sed nec culpe aut macule notam. Si dominus archiepiscopus modernus potencia sue auctoritatis donatas ac perpetuo inscriptas decimas ecclesie Sandomiriensi abstulit, et si capitulum Sandomiriense, me nedum instigante sed nec suadente capitulum Cracoviense vexat, nec obligaverim me prefatis ecclesiis de aliqua indempnitate, sed utriusque profectum sollicitaverim, procuraverim, ordinaverim et effecerim bono simplici et fideli corde meis fatigis, periculis et expensis nec sum tante fortitudinis et auctoritatis, ut possim aut debeam auctoritatem et impressionem archiepiscopalem mea potencia reprimere et voluntatem capituli Sandomiriensis rescindere et annullare. Item accedit ad verificacionem omnium premissorum ad lucidiorem innocenciam ipsius Johannis Dlugosch demonstrandam, quod ipse Johannes Dlugosch 
duas villas optimas, videlicet Okolyna $^{4}$ et Goyczow ${ }^{5}$, emit pro mansionariis apud abbatem Suleouiensem ${ }^{6}$, quarum quelibet est ita bona sicut mille. marce latorum grossorum et ipsas de manibus adversariorum annis octo litigando suis expensis et fatigis et periculis liberavit; item pro eisdem mansionariis Sandomiriensibus domum optimam a fundamentis inicians muravit, que constat plus quam duo milia marcas, de quo se refert ad regesta dispersatorum; item emit unam domum et aream pro mansionariis ${ }^{7}$ a domino Lysczaliewsky perpetuo. Ex quibus omnibus, pater reverendissime, paternitas vestra iusto iudicio decernat, si ipse Johannes Dlugosch ad eviccionem et indempnitatem alterius, vel violencia, vel negligencia commissa, debeat artari et pro officio suo in utramque ecclesiam exhibito gravari, vexari et confudi.

Episcop. Crac. 3 k. 162v-163a.

Stanislaus Zarogowsky ${ }^{1}$ civis de Cracovia ad acta presencia et coram domino personaliter constitutus"sponte et libere recognovit et palam confessus est duos marcas puri auri vadii magis vel minus sex scotits puri auri veri et iusti ponderis reverendo et venerabili viris dominis Stanislao de Swiradzicze preposito Kyelczensi administratori sede vacante ecclesie Cracoviensis, Johanni de Goslaw ${ }^{2}$ custodi Vislicziensi canonicisque Cracoviensibus tanquam executoribus testamenti venerabilis viri domini Johannis Dlugosch canonici Cracoviensis teneri et obligari. Quasquidem duas marcas auri vadii eisdem dominis Stanislao de Swiradzicze et Johanni Goslawsky executoribus hinc ad festum Nativitatis Cristi proxime instans et affuturum, omnibus excepcionibus, appellacionibus, ingeniis coloribus, litteris regalibus iuris et facti, altercacionibus, diffugiis, allegacionibus quoquomodo dicta solucione impedire valentibus per expressum renunciando, sub censuris ecclesiasticis se solvere obligavit. Presentibus discretis Johanne de Dambyani ${ }^{3}$ actu presbiteri Johanne de Jacubow ${ }^{4}$, Stanislao de Baruchowo ${ }^{5}$, Mathia de Schewnya et me Jacobo de Bodzanczin ${ }^{6}$, notariis publicis domini administratoris testibus ad premissa.

Offic. Crac. 14 s. 304.

4 Okalina, wieś w pow. opatowskim.

5 Gojców, wieś w pow. sandomierskim. s. 393.

Jan, opat sulejowski: Regesta (BS) $\mathrm{nr} 375$; Cod. Ep. II, s. 272; Lib. Ben. I,

7 Lib. Ben. I, s. 397.

751 Stanisław Zarogowski z Krakowa (1480-1489): Regesta (BS) nr 94 (dodatek). Słownik historyczno-geograficzny województwa krakowskiego w średniowieczu, cz. 1, Wrocław 1980 , s. 92-93.

2 Jan Gosławski h. Wieniawa, kanonik krakowski (1479), kustosz wiślicki i kurzelowski, dziekan sądecki, pleban w Bochni, prebendarz w Pełczyskach, wikariusz generalny krakowski (1498-1501), zm. w r. 1505: Przybyszewski, Wypisy I, s. 62.

${ }^{3}$ Jan z Dębian (Dębieński) h. Nieczuja, kapelan królowej Elżbiety, notariusz publiczny (1488), pleban w Brzyskach, prebendarz kaplicy Swiętokrzyskiej na Wawelu, kanonik sandomierski, zm. w r. 1520: Przybyszewski, Wypisy I, s. 94.

4 Jan Jakubowski, notariusz (1480-1488), prokurator konsystorza krakowskiego (1495-1496), kanonik krakowski (1516-1523): Kod. UJ III, s. 86, 101, 129, 134, 142.

5 Stanisław z Baruchowa, kleryk (1488): Kod. UJ III, s. 142.

6 Jakub z Bodzętyna, skryba i notariusz (1487-1493): Przybyszewski, Wypisy I, s. 83, 88; Cracovia artificum, nr 165, 1126. 
Nicolaus Szelwa ${ }^{1}$ de Prandnyk ad acta presencia personaliter comparens sponte, libere et de certa sua sciencia recognovit et palam confessus est ducentos florenos Vngaricales puri auri veri et iusti ponderis per venerabilem dominum Johannem Dlugosch cánonicum Cracoviensem ad bona hereditaria, que nunc ipse possidet et tenet, datos nec non quinquaginta marcas absque duobus marcis peccuniarum communis peccunie, in qualibet marca computando quadraginta octo grossos pecuniarum, certi debiti mutuati reverendo patri et venerabili dominis Stanislao de Swiradzicze preposito Kyelczensi et administratori Johanni Goslawsky de Goslaw custodi Vislicziensi et canonicis ecclesie Cracoviensis kathedralis ac executoribus testamenti reverendi patris domini olim Johannis Dlugosch canonici Cracoviensis teneri et obligari. Quosquidem ducentos florenos in eodem auro et pondere ac quinquaginta marcas absque duabus certi debiti pretextu dictorum bonorum in Prandnyk consistencium et per ipsum Jacobum Szelwa possessorum et in possessione sua habitorum eisdem dominis Stanislao de Swiradzicze etc. Johanni Goslawski etc. executoribus testamenti dicti olim Johannis Dlugosch a fes o Nativitatis Christi proxime instante et affuturo infra hinc et aliud festum Nativitatis Christi per quattuor annos proxime venturum et instans sub censuris ecclesiasticis et divisione dictorum bonorum in Prandnyk se solvere obligat, alias in defectu solucionis per quatuor annos in festo Nativitatis Christi ab isto proxime venturo dictorum ducentorum florenorum et quinquaginta marcarum per ipsum Jacobum Szelwa obligantem prescriptis dominis fiende actualiterque et cum effectu prestande et exhibende, extunc dicta bona per eum possessa et dicta Prandnyk consistencia et iacencia libere et sponte absque quavis evocacione ad ius terrestre et quovis impedimento intromissionem in dicta bona facienti proculmoto, eisdem dominis Stanislao de Swiradzicze preposito Kyelczensi et Johanni Goslawsky etc. dimittere, evacuare de eisdemque cedere et per expressum renunciare necnon inscripcionem et huiusmodi obligacionem occasione premissorum ducentorum florenorum et quinquaginta marcarum in iure terrestri et alias castri Cracoviensis terminos proxime celebraturos in castro Crácoviensi dictis dominis superius expressis, omnibus excepcionibus et litteris regalibus reiectis, idem Jacobus Szelwa sub eisdem censuris ecclesiasticis facere obligat. Presentibus honorabilibus et nobili dominis Johanne de Dambyany actu presbitero, Petro de Skarbimiria $^{2}$ notariis Johanni Woszczynsky, Paulo familiaribus et me Jacobo de Bodzanczin notario publico domini administratoris testibus aci premissa vocatis.

Offic. Crac. 14 s. $428-429$.

\section{7}

$2 \times 1496$

Venerabiles domini Vincencius Przerambsky ${ }^{1}$, Johannes Ludbransky ${ }^{2}$ decretorum doctor Cracovienses et Sandomirienses canonici et Mathias Drze-

76 i Mikolaj i Jakub Selwowie, właściciele folwarku na Prądniku Czerwonym, dziś dzielnicy Krakowa: Regesta (BS) nr 413; Lib. Ben. I, s. 603.

2 Piotr, syn Stanisława ze Skalbmierza, notariusz (1489), pleban w Zakrzewie: Przybyszewski, Wypisy I, s. 88.

77 1 Wincenty Przerębski h. Nowina, kanonik gnieźnieński, krakowski (1479), podkanclerzy (1497-1498), biskup płocki (1498-1504), biskup kujawski (1504-1513): Przybyszewski, Wypisy, I, s. 103.

2 Jan Lubrański h. Godziemba, kanonik krakowski (1487), biskup płocki (1498), 
wiczki $^{3}$ cantor prefate ecclesie Sandomiriensis ad acta presencia et coram domino personaliter constituti suo et tocius capituli predicte ecclesie Sandomiriensis nominibus obligaverunt se omnes manu coniuncta et indivisa unus pro alio cavendo et se principalem debitorem ponendo, infra hinc et unius mensis spacium mandatum sufficiens in eorum proprias personas nomine tocius capituli ecclesie Sandomiriensis antedicte ad recipiendum et levandum tricentos florenos in auro et in peccuniis ad acta presencia et in manibus domini per venerabilem dominum Johannem Goslawski canonicum Cracoviensem olim domini Dlugosii testamenti executorem parentem sentencie diffinitive contra eum et pro parte dicti capituli Sandomiriensis per dominum officialem ${ }^{4}$ late, repositos et similiter quittanciam et eviccionem sub titulo et sigillo prefati capituli Sandomiriensis scriptam ad ipsum dominum Johannem Goslawsky a quibuscumque personis, cuiuscumque status et eminencie aut dignitatis existant, occasione predictorum tricentorum florenorum nec non bonorum predii Pradnik quattuor laneorum ibidem siti per eundem dominum Johannem Goslawsky resignatorum evincendam et in quolibet iure spirituali et seculari intercedendam mittere et destinare ac ipsi domino Johanni Goslawsky presentare aut ad acta presencia reponere sub excommunicacionis pena et dictorum tricentorum florenorum restitucione reali et effectuali, in defectu missionem predicti mandati ac quittancie et eviccionem fiendam; ad quam penam se sponte submiserunt. Quos quidem dominos obligantes, incontinenti dominus Petrus de Myechow ${ }^{5}$ psaltarista ecclesie Cracoviensis predicte de mandato domini officialis predicti monuit et requisivit, quatenus huiusmodi obligacioni per eos superius facte realiter et cum effectu pareant ad tempus super contentum. Quaquidem obligacione facta per dictos dominos canonicos et cantorem dominus officialis memoratus eosdem tricentos florenos ipsis dominis obligantibus recipiendos decrevit ac eos in manus prefati domini Johannis Ludbransky dedit et contulit. Presentibus dominis Johanne de Wodzislaw ${ }^{6}$ decretorum doctore, Nicolao Jassyensky, Jeronimo Drzewiczky ${ }^{7}$, Johanne Piekarsky, Johanne Gromadzky ${ }^{8}$ et Nicolao Nagorski dicti domini Johannis Ludbransky notario ac me Johanne de Michalow ${ }^{9}$ actus presentis scriba testibus.

Offic. Crac. 15 s. 429.

biskup poznański, założyciel akademii w Poznaniu, zm. w r. 1520: PSB XVIII, s. $81-84$.

3 Maciej Drzewicki h. Ciołek, kanclerz wielki koronny (1511), biskup przemyski, włocławski, arcybiskup gnieźnieński (1531-1535): PSB V, s. 409-412.

4 Jan Starzechowski ze Starzechowic, doktor dekretów, kanonik (1482) i oficjał generalny krakowski (1493-1501), prokurator kapituły krakowskiej (1503) zm. W r. ${ }^{1504}$ : PSB X, s. 479.

5 Piotr z Miechowa, syn Błażeja, notariusz (1477), psałterzysta katedralny krakowski (1490-1494): Kod. UJ III, s. 55, 58, 198; Cracovia artificum, nr 1049, 1050.

6 Jan z Wodzisławia, student Uniwersytetu Krakowskiego (1471), doktor dekretów (1491), proboszcz św. Marii Magdaleny w Krakowie (1495) w Niegardowie i Przegini, zm. w r. 1507: PSB X, s. 490-491.

7 Hieronim Drzewicki, syn Jakuba, student Uniwersytetu Krakowskiego (1490): AS II, s. 1.

8 Jan Gromadzki (z Gromadzic) magister artium Uniwersytetu Krakowskiego (1479), altarysta w kościele św. Floriana na Kleparzu (1490), zm. w r. 1497: LP, s. 82, 85; Acta rectorialia, nr $965 \mathrm{nn}$; Kod. UJ III, s. 160.

9 Jan Michałowski, syn Macieja, notariusz 1494-1502), zm. w r. 1502: Kod. U.J III, s. 154, 198, 199; Przybyszewski, Wypisy I, s. 109. 
Venerabilis dominus Johannes Goslawski canonicus Cracoviensis executor testamenti olim venerabilis domini Johannis Dlugosch canonici Cracoviensis ad acta presencia personaliter constitutus sponte et libere recognoscens se habere et possidere certum vadium, videlicet decem novem fibulas ad modum medii pomi de auro puro Hungaricali conflato dispositas cathenatim elaboratas per milites ferri solitas; prefato olim domino Dlugossio canonico Cracoviensi per venerabilem olim dominum Johannem Regula scolasticum Skarbimiriensem in quatuordecim marcis peccuniarum propositum et invadiatum; quasquidem XIX fibulas aureas idem olim dominus scolasticus a magnifico olim domino Andrea Pinczowski ${ }^{1}$ castellano Sandecensi in certis debitis et, ut prefatus dominus Johannes Goslawski dicebat, in centum marcis peccuniarum pro certis decimis retentis habuit et tenuit invadiatas et similiter propositas, easdem decem novem fibulas ad similitudinem pomi de auro elaboratas venerabili domino Johanni Starzechowski canonico Cracoviensi et officiali moderno generali prefati olim domini scolastici testamenti executori exemendas admisit; quiquidem dominus Johannes Starzechowsky, ut dicebat, de consensu et voluntate aliorum executorum testamenti prefati domini scolastici prefatas decem novem fibulas aureas ab eodem domino Johanne Goslawsky redemit et exemit nec non huiusmodi quatuordecim marcas, in quibus erant impignorate, prefato domino Johanni Goslawsky realiter tradidit et exsolvit, de quibus eum idem dominus Johannes Goslawsky quittavit et presentibus quittat ac ipsum aurum supramencionatum ei realiter tradidit et cum effectu; cuiusquidem auri recepti occasione memoratus dominus Joannes Starzechowski suo et aliorum suorum coexecutorum nominibus cavendo, de illorum rato eundem Johannem Goslawsky ab omnibus et singulis personis in quocumque iudicio et coram omni seu iudice seu iudicibus, si et in quantum impeditus et molestatus per aliquem fuerit, suis propriis sumptibus et expensis intercedere, evincere ac indempnem reddere promisit, ac se et suos coexecutores obligavit sub excommunicacionis pena in eum per iudicem et competentem ferenda. Presentibus ibidem honorabilibus dominis Andrea de Pilzno $^{2}$ vicario perpetuo ecclesie Cracoviensis cancelario, Sebastiano de Oleschinky ${ }^{3}$, Martino de Lancicia ${ }^{4}$, Johanne Pyekarsky et me Johanne Mathie de Michalow notariis consistorii testibus.

Offic. Crac. 15 s. $471-472$.

78 1 Andrzej Pinczowski z Oleśnicy, starosta sądecki (1484-1496): Fedorowicz, s. 43.

2 Andrzej z Pilzna, wikariusz katedralny krakowski i notariusz (1481-1498): Przybyszewski, Wypisy I, s. 106-107; Cracovia artificum, nr 1235, 1282, 1337.

3 Sebastian z Oleśników w Lubelskim (1497): Marticularium Regni Poloniae Summaria. Ed. T. Wierzbowski. T. 2, Warszawa 1907, nr 821.

4 Marcin z Eęczycy, notariusz (1496): Kod. UJ III, s. 154; Cracovia artificum, nr 1282. 
EXTRAITS DES REGISTRES JURIDIQUES DE LA CURIE METROPOLITAINE DE CRACOVIE, À UTILISER DANS UNE BIOGRAPHIE DE JEAN DŁUGOSZ

Ré s u m é

Le recueil choisi des annotations provenant des „Acta officialia” et „Acta episcopalia", est pour ainsi dire le complément d'un recueil semblable, publié par M. Bobrzyński et St. Smolka dans leur ouvrage sur Jan Długosz à Cracovie en 1893. Dans les registres juridiques du consistoire cracovien, le nom de Jan Długosz (1415-1480) est souvent mentionné, en relation avec les fonctions qu'il occupait auprès des évêques de Cracovie, en particulier du card. Z. Oleśnicki, dont il fut à partir de 1431 le préposé principal à la chancellerie, puis le secrétaire et le chancelier.

Grâce au contenu des annotations, nous prenons connaissance avec diverses affaires touchant la famille Długosz, la plupart des détails se rapportent cependant à son frère cadet et homonyme, Jan Długosz († 1471), qui a été son adjoint et habitait avec lui. Les autres renseignements concernent des transactions matérielles et financières. Elles comprenaient également des affaires personnelles de Długosz lui-même, et aussi celles de particuliers, y compris celles de l'évêque de Cracovie, du chapitre cathédral, ou encore des congrégations religieuses. Les dernières annotations, datées des annés 1488-1497, ont pour objet l'exécution du testament laissé par l'historien.

Les annotations publiées ci-dessous apportent, quant à elles, des détails inédits à la biographie du plus grand historien polonais de la fin du Moyen-Age, Jan Długosz, dont nous fêtons précisément le cinq centième anniversaire de la mort. 